\title{
Diagnosing Mesoscale Vertical Motion from Horizontal Velocity and Density Data
}

\author{
Enric Pallàs Sanz and Álvaro Viúdez \\ Institut de Ciències del Mar, Barcelona, Spain
}

(Manuscript received 29 July 2004, in final form 10 March 2005)

\begin{abstract}
The mesoscale vertical velocity is obtained by solving a generalized omega equation ( $\omega$ equation) using density and horizontal velocity data from three consecutive quasi-synoptic high-resolution surveys in the Alboran Sea. The Atlantic Jet (AJ) and the northern part of the Western Alboran Gyre (WAG) were observed as a large density anticyclonic front extending down to $200-230 \mathrm{~m}$. The horizontal velocity $\mathbf{u}_{h}$ in the AJ reached maxima of $1.2 \mathrm{~m} \mathrm{~s}^{-1}$ for the three surveys, with extreme Rossby numbers of $\zeta / f \approx-0.9$ in the WAG and +0.9 in the AJ (where $\zeta$ is the vertical vorticity and $f$ is the Coriolis parameter). The generalized $\omega$ equation includes the ageostrophic horizontal flow. It is found that the most important "forcing" term in this equation is $\left(f \zeta_{\mathrm{ph}}+\nabla_{h} \varrho\right) \cdot \nabla_{h}^{2} \mathbf{u}_{h}$, where $\zeta_{\mathrm{ph}}$ is the horizontal (pseudo) vorticity and $\varrho$ is the buoyancy. This term is related to the horizontal advection of vertical vorticity by the vertical shear velocity, $\mathbf{u}_{h z} \cdot \nabla_{h} \zeta$. Extreme values of the diagnosed vertical velocity $w$ were located at $80-100 \mathrm{~m}$ with $\max \{w\} \subset[34,45]$ and $\min \{w\} \subset[-64,-34] \mathrm{m}^{-1}$ day $^{-1}$. Comparison with the quasigeostrophic (QG) $\omega$ equation shows that, because of the large Rossby numbers, non-QG terms are important. The differences between $w$ and the QG vertical velocity are mainly related to the divergence of the ageostrophic part of the total $\mathbf{Q}$ vector $\left(\mathbf{Q}_{h} \equiv \boldsymbol{\nabla}_{h} \mathbf{u}_{h} \cdot \nabla_{h} \varrho\right)$ in the $\omega$ equation.
\end{abstract}

\section{Introduction}

Mesoscale vertical motion in the ocean is typically four orders of magnitude smaller than the mesoscale horizontal velocity. This vertical velocity $w$ is, however, important in oligotrophic oceanic areas since it advects upward cold waters rich in dissolved and particulate matter from the bottom layer to the photic zone, controlling the size structure of phytoplankton in the oceanic mesoscale. Obtaining direct measurements of $w$ is, because of its small magnitude, technically very difficult and, consequently, indirect theoretical methods have been conceived to estimate $w$. These methods were initially developed for atmospheric applications (Panofsky 1946; Sherman 1953) and later applied to the ocean circulation (Bryden 1980; Leach 1987; Allen 1993; Lindstrom and Watts 1994).

For synoptic-scale motions that are hydrostatic and nearly geostrophic, one of the most successful methods to obtain an approximative $w$ is solving the quasigeo-

Corresponding author address: Enric Pallàs Sanz, Institut de Ciències del Mar, P. Marítim 37, 08003-Barcelona, Spain.

E-mail: epallas@icm.csic.es strophic (QG) $\omega$ equation, for the QG vertical velocity $w^{q}$, which only requires the density field $\rho$ (Gill 1982, his chapter 12; Holton 1992, his section 6.4). The first formulation of the QG $\omega$ equation presented an undesirable cancellation of terms (Trenberth 1978), which lead to its reformulation (Hoskins et al. 1978) using the divergence of the geostrophic $\mathbf{Q}$ vector $\mathbf{Q}_{h}^{g} \equiv$ $\boldsymbol{\nabla}_{h} \mathbf{u}_{h}^{g} \cdot \nabla_{h} \varrho$, where $\mathbf{u}_{h}^{g}$ is the horizontal geostrophic velocity, $\varrho$ is buoyancy, and subscript $h$ stands for the horizontal component. More recently, Viúdez et al. (1996c) explained that this cancellation of terms was a result of having equated the local, instead of the material, rates of change of the geostrophic differential vorticity derived from the momentum and density conservation equations, and they proposed a generalized $\omega$ equation in terms of the material rate of change of the ageostrophic differential vorticity. It is an approximation to this generalized $\omega$ equation that is solved here including the experimental horizontal velocity. A semigeostrophic (SG) $\omega$ equation, which includes the ageostrophic advection of $\mathbf{u}_{h}^{g}$ was derived by Hoskins and Draghici (1977). Other generalized forms of the $\omega$ equation involving density and horizontal velocity data have been formulated by Davies-Jones (1991) and Xu (1992). 
Both the QG and SG $\omega$ equations have been applied to estimate $w$ in oceanic fronts, gyres, and baroclinic waves. Values of $w^{q}$ of up to $40 \mathrm{~m} \mathrm{day}^{-1}$ were found in a strong front in the Sargasso Sea using a twodimensional version of the QG $\omega$ equation (Pollard and Regier 1992). The three-dimensional QG $\omega$ equation was solved using density data from the Alboran Sea, resulting in maximum $w^{q}$ of about $10-20 \mathrm{~m}$ day $^{-1}$ associated to small-scale meanders in the Atlantic Jet (Viúdez et al. 1996a). Mesoscale features of the California Current System gave rise to maxima $w^{q}$ of 40-45 $\mathrm{m}_{\text {day }}{ }^{-1}$ (Shearman et al. 1999, 2000). Horizontal velocity [shipboard acoustic Doppler current profiler (ADCP)] and SeaSoar conductivity-temperaturedepth (CTD) data were used by Allen and Smeed (1996) to obtain the "absolute" geostrophic velocity and to diagnose $w^{q}$ in the Iceland-Færœs front, obtaining values of $w^{q}$ of up to $90 \mathrm{~m} \mathrm{day}^{-1}\left( \pm 30 \mathrm{~m} \mathrm{day}^{-1}\right)$ associated to unstable meanders and eddies. In the Azores front Rudnik (1996) found, using also CTD and ADCP data, maxima $w^{q}$ of $\sim 20 \mathrm{~m} \mathrm{day}^{-1}$ at $200-300 \mathrm{~m}$.

The accuracy of both QG and SG solutions has been addressed using primitive equation (PE) numerical models. Pinot et al. (1996) conducted PE simulations of frontal instabilities and concluded that the SG $\omega$ equation was the most useful method to estimate $w$ from the density field. Viúdez et al. (1996b), using a PE dataassimilation technique to diagnose $w$ in the Alboran Sea, with flat bottom boundary conditions at $200 \mathrm{~m}$, found high correlation coefficients $(\sim 0.98)$ between $w^{q}$ and the PE-diagnosed $w$. More recent PE simulations (Viúdez and Dritschel 2004) revealed that both QG and SG solutions underestimate (overestimate) $w$ when the potential vorticity is negative (positive). They also found that, when the phase or propagation speed of cyclones and anticyclones is large, as in the case of dipolar vortices, $w^{q}$ may be more accurate than the SG $w$. Based on these PE results and on the generalized $\omega$ equation in terms of the rate of change of ageostrophic differential vorticity they proposed an approximate $\omega$ equation valid when both density and horizontal velocity fields are known. This is the $\omega$ equation analyzed in this work using experimental data.

In this paper we carry out a first analysis of the $\omega$ equation using experimental high-resolution horizontal velocity (ADCP) and density (SeaSoar) data from three consecutive surveys in the Alboran Sea. The three surveys sampled the Atlantic Jet (AJ) and the northern part of the Western Alboran Gyre (WAG). Section 2 briefly describes the dataset and sampling methods. In section 3 we include the derivation of the generalized $\omega$ equation (section $3 \mathrm{a}$ ), the approxima-
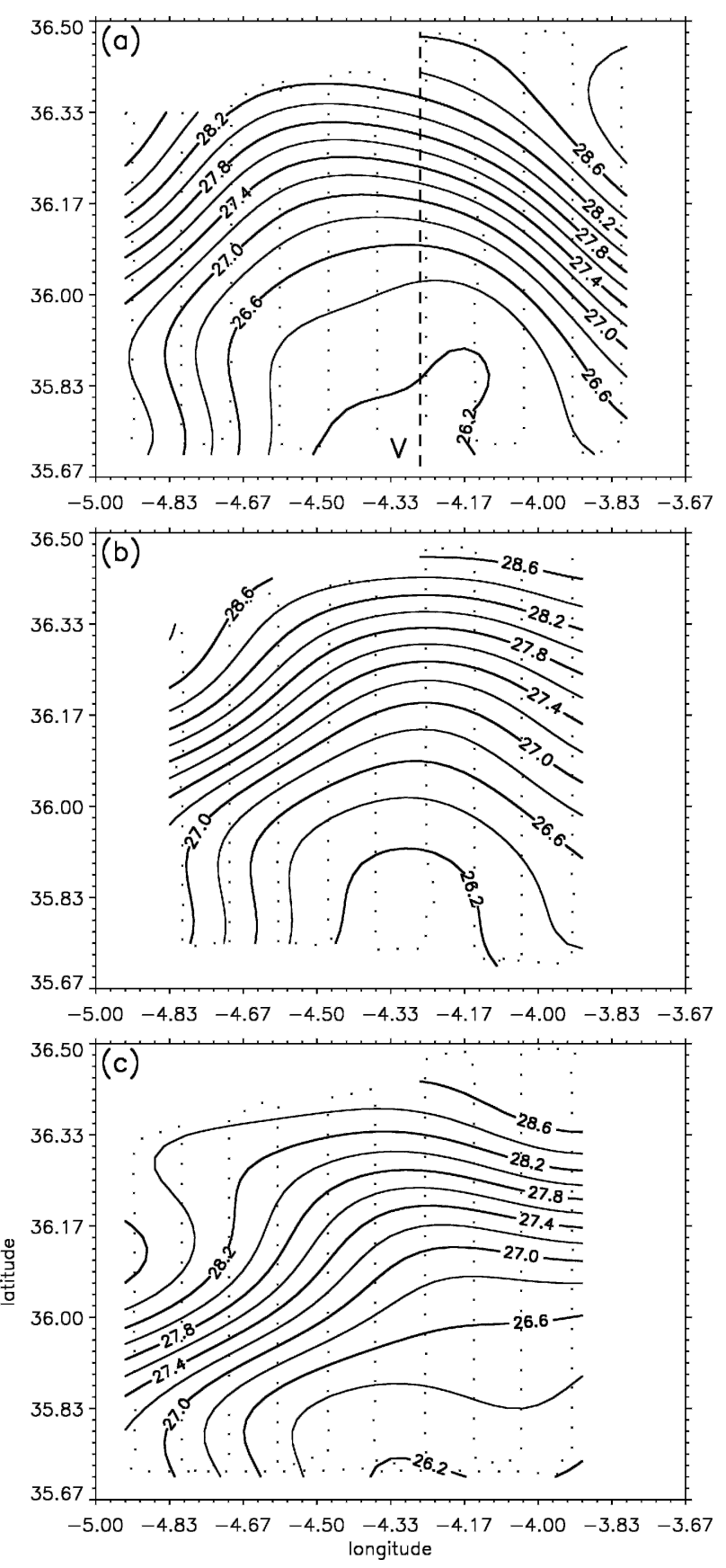

FIG. 1. Horizontal distribution of potential density anomaly $\left(\sigma_{\theta}\right)$ at $z=-100 \mathrm{~m}$ for the three consecutive surveys: (a) 1, (b) 2 , and (c) 3. Dots indicate the SeaSoar interpolated "stations." Vertical section V is referenced. Labels are in degrees. Contour interval $\Delta$ $=0.2 \mathrm{~kg} \mathrm{~m}^{-3}$.

tions involved in the $\omega$ equation used (section $3 b$ ), the analysis of the different terms in the $\omega$ equation and the vertical velocity obtained (section $3 \mathrm{c}$ ), and the comparison with the QG vertical velocity $w^{q}$ (section $3 d$ ). Concluding remarks are given in section 4 . 

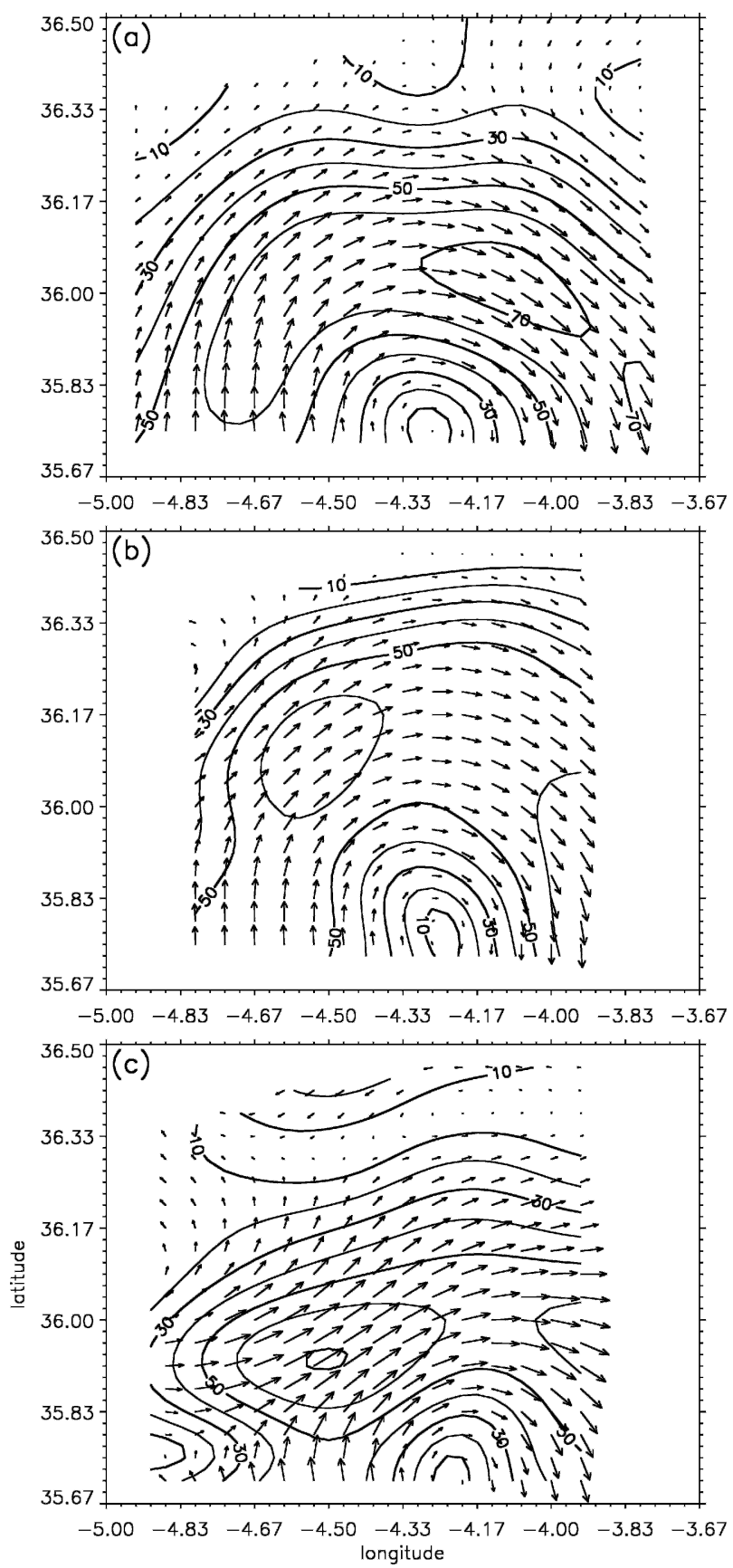

FIG. 2. Horizontal distribution of $\mathbf{u}_{h}$ at $z=-100 \mathrm{~m}$ for the three surveys. In this and subsequent horizontal vector distributions only every other vector is plotted. Isolines indicate the speed $\left|\mathbf{u}_{h}\right|$ $\left(\Delta=10 \mathrm{~cm} \mathrm{~s}^{-1}\right)$.

\section{Dataset}

For a background description of the physical oceanography of the Alboran Sea we refer to Parrilla and Kinder (1987), and for a three-dimensional description of the AJ and WAG to Viúdez et al. (1996a) and Viú-

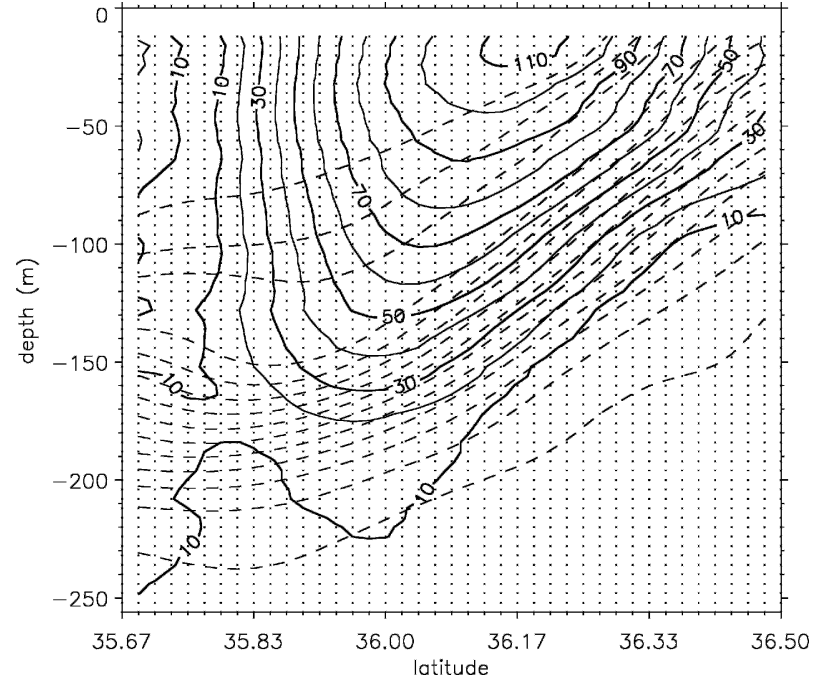

FIG. 3. Eastward velocity $\left(u, \Delta=10 \mathrm{~cm} \mathrm{~s}^{-1}\right.$, solid contour isolines) on vertical section $\mathrm{V}$ for survey 1 (Fig. 1) and potential density $\left(\sigma_{\theta}, \Delta=0.2 \mathrm{~kg} \mathrm{~m}^{-3}\right.$, dashed isolines). Dots indicate the interpolation grid.

dez and Haney (1997). An explanation of the upper circulation in terms of the tendency of the $\mathrm{AJ}$ to acquire negative curvature is given in Viúdez et al. (1998a), and a recent Lagrangian description in García Lafuente and Delgado (2004).

The dataset we have used were obtained during three consecutive surveys from 30 September to 14 October 1996. Every survey was completed in approximately 3 days, sampling an area of about $100 \times 80 \mathrm{~km}^{2}$. A SeaSoar mounted CTD and a vessel-mounted $150 \mathrm{-kHz}$ RDI ADCP sampled, from west to east, 11 parallel meridional legs, $10 \mathrm{~km}$ apart. The SeaSoar was towed undulating from the surface $(5 \mathrm{~m})$ to $\sim 350 \mathrm{~m}$ with an along-track resolution of $4 \mathrm{~km}$. The ADCP undulated between 12 and $\sim 328 \mathrm{~m}$ with an along-track resolution of $2 \mathrm{~km}$. The processed horizontal velocities were configured in 80 levels with a vertical resolution of 4 dbar (accuracy of $\sim 1 \mathrm{~cm} \mathrm{~s}^{-1}$ ). The raw SeaSoar data were averaged into 8-dbar bins. After filtering of outliers, the dataset contained 238 SeaSoar and 352 current profiles. Further details of the ADCP and SeaSoar calibration and data processing are given in Allen et al. (1997). Several recent studies have made use of this dataset in the Alboran Sea addressing the balance of the horizontal momentum in the AJ-WAG system (Viúdez et al. 2000); the three-dimensional ageostrophic circulation (Gomis et al. 2001); the synopticity of the dataset (Rixen et al. 2001b); and the surface distribution of chlorophyll, particles, and gelbstoff (Ruíz et al. 2001).

For this study the SeaSoar vertical profiles were linearly interpolated every $4 \mathrm{~m}$ from $12 \mathrm{~m}$ down to $\sim 256$ 

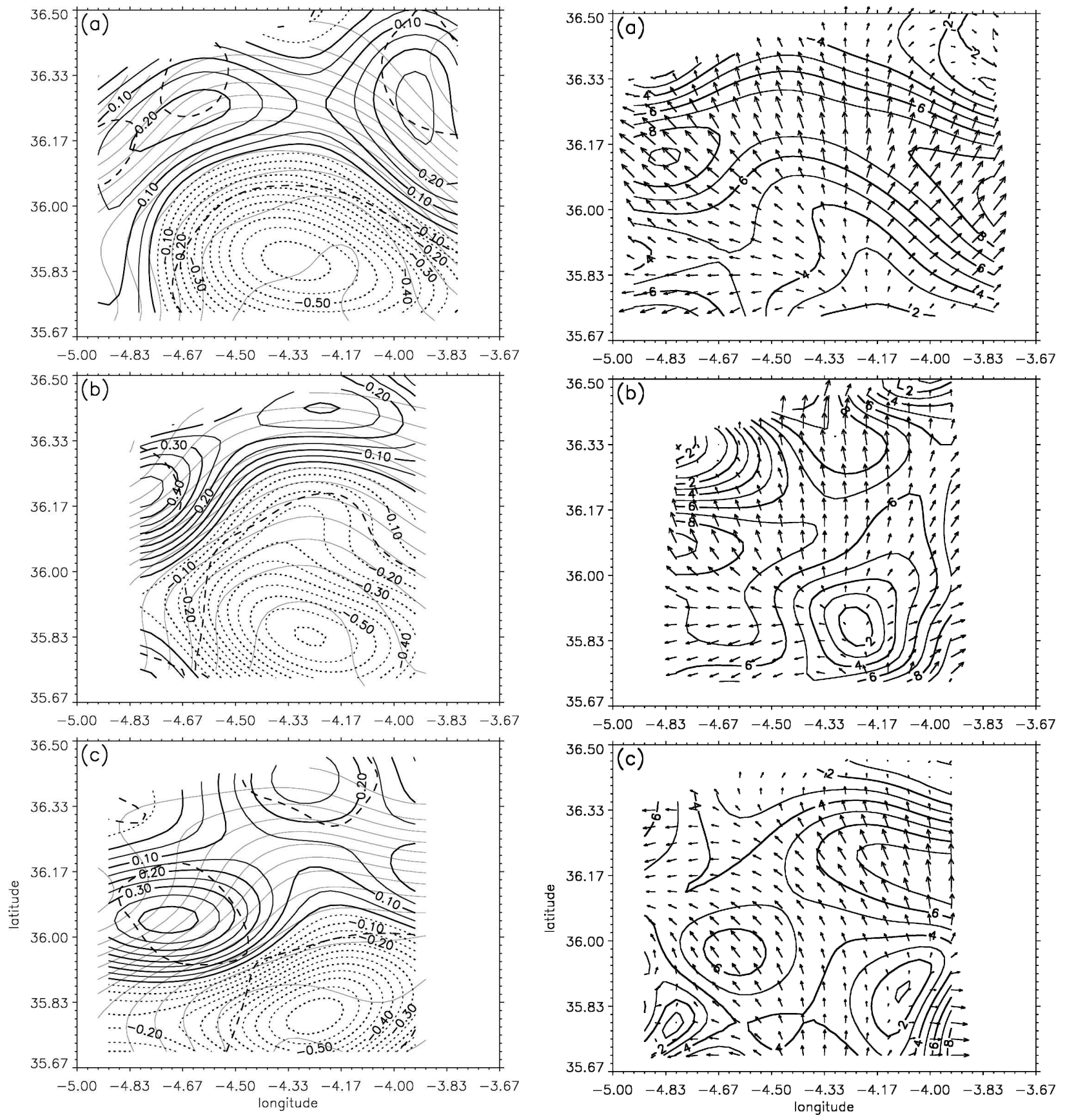

FIG. 4. The dimensionless relative vorticity $\zeta / f$ for the three surveys $(\Delta=0.05, z=-100 \mathrm{~m})$. Relative vorticity ranges from $-0.6 f$ to $+0.45 f$ at this depth. The potential density anomaly $\sigma_{\theta}$ (unlabeled continuous isolines) and contours of $Q=0$ (dashed isolines) are included.

$\mathrm{m}$, which is the layer where the main thermohaline front is located. Potential temperature, salinity, and ADCP horizontal velocity components were then horizontally interpolated onto a regular grid using a method of successive corrections (Pedder 1989, 1993). This in-

FIG. 5. Term $f \zeta_{\text {ph }}$ for the three surveys. Isolines indicate the magnitude $\left|f \zeta_{\mathrm{ph}}\right|\left(\Delta=10^{-7} \mathrm{~s}^{-2}, z=-100 \mathrm{~m}\right)$.

terpolation procedure depends on a selected characteristic scale $\left(L_{s}\right)$ and operates as a low-pass filter for wavelengths smaller than $L_{s}$. Consistently with previous studies (Viúdez et al. 1996a; Gomis et al. 2001) we have used $L_{s}=20 \mathrm{~km}$. The three-dimensional grid has $\left(n_{X}, n_{Y}, n_{Z}\right)=(41,41,61)$ nodes with grid sizes $\left(\Delta_{X}, \Delta_{Y}\right.$, $\left.\Delta_{Z}\right)=(\sim 2.9 \mathrm{~km}, \sim 2.3 \mathrm{~km}, 4 \mathrm{~m})$. 

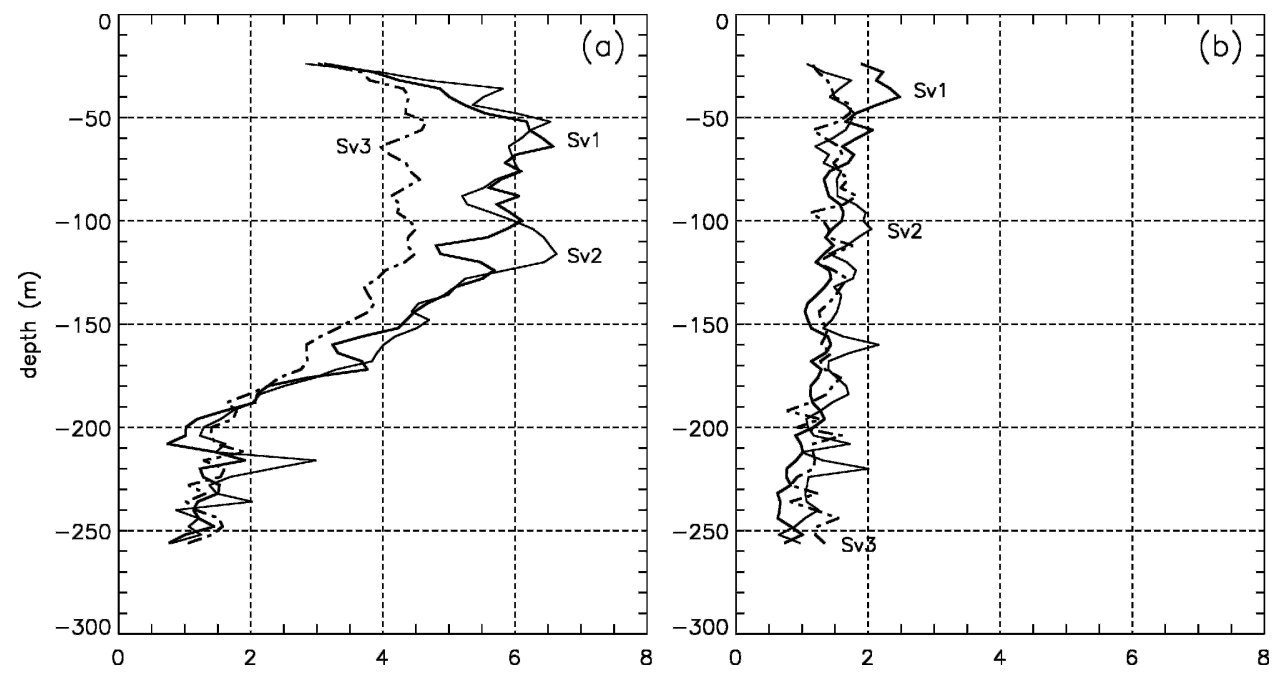

FIG. 6. Horizontal average of (a) $|\partial| \mathbf{u}_{h}|/ \partial z|$ and (b) $\left|\mathbf{u}_{h} \Theta_{Z}\right|$ as a function of depth for the three surveys $\left(10^{-3} \mathrm{~s}^{-1}\right.$; the average includes the grid points with $\left.\left|\mathbf{u}_{h}\right|>5 \mathrm{~cm} \mathrm{~s}^{-1}\right)$.

\section{a. Density field}

The gridded potential density anomaly $\sigma_{\theta}$ was calculated from the gridded potential temperature and salinity fields [computed following Bryden (1973) and UNESCO (1981)]. The AJ-WAG interface appears as an intense density front (Fig. 1), which separates the denser old modified Atlantic water [MAW; here with $\left.\sigma_{\theta} \subset(27.2,28.4)\right]$ in the northern part, from the lighter recent MAW $\left[\sigma_{\theta} \subset(26.1,27.0)\right]$ in the south (Gascard and Richez 1985). The density interface AJ-WAG has a density anomaly interval $\Delta_{\sigma} \simeq(27.0,27.2)$. In survey 1 (Fig. 1a) the AJ enters the Alboran Sea through the Strait of Gibraltar and gently surrounds the northern part of a well-developed WAG. In surveys 2 and 3 (Figs. 1b,c) the AJ impinges more directly on the core of the WAG and some eastward gyre migration is observed. Similar WAG migrations have been recently confirmed from time series of thermal satellite imagery during October-November 1996 (Viúdez et al. 1998a) and October 1997 (Vargas-Yáñez et al. 2002).

\section{b. Horizontal velocity}

The horizontal velocity $\mathbf{u}_{h}$ at $z=-100 \mathrm{~m}$ reaches maxima of 70,60 , and $70 \mathrm{~cm} \mathrm{~s}^{-1}$ in surveys 1,2 , and 3 , respectively (Fig. 2). This current extends down to $\sim 200 \mathrm{~m}$, where its vertical gradient becomes negligible. In surveys 1 and 2 the circulation is mostly anticyclonic. In survey 3 , as a consequence of the WAG displacement, the anticyclonic circulation is restrained to the southeastern part. Weak cyclonic circulation is also present in the northeast $\left(36.33^{\circ} \mathrm{N},-3.83^{\circ} \mathrm{W}\right)$ in survey 1 and in the northwest $\left(36.17^{\circ} \mathrm{N},-4.83^{\circ} \mathrm{W}\right)$ in survey 3 (Figs. 2a,c). Horizontal velocity maxima (larger than $110 \mathrm{~cm} \mathrm{~s}^{-1}$; Fig. 3) are located in the upper $30 \mathrm{~m}$ in the northern WAG, with maximum vertical gradients at about $100 \mathrm{~m}$.

Comparison with the geostrophic velocity $\mathbf{u}_{h}^{g}$ (referenced to 256-m no-motion level; Viúdez et al. 2000) revealed that, in the three surveys, the flow is generally supergeostrophic $\left(\left|\mathbf{u}_{h}\right|>\left|\mathbf{u}_{h}^{g}\right|\right)$, except at the core of the WAG and in the southwestern corner in survey 3 $\left(36.05^{\circ} \mathrm{N},-4.67^{\circ} \mathrm{W}\right)$ where $\mathbf{u}_{h}$ is subgeostrophic $\left(\left|\mathbf{u}_{h}\right|<\right.$ $\left.\left|\mathbf{u}_{h}^{g}\right|\right)$.

\section{c. Vertical vorticity}

The scaled relative vorticity field, or Rossby number, $\zeta / f$ (where $\zeta=v_{x}-u_{y}$; subscripts $x, y$, and $z$ mean the partial derivative) at $100 \mathrm{~m}$ has minima of -0.6 located at the core of the WAG (Fig. 4). In survey 1, two relative maxima, between 0.2 and 0.25 , develop on both sides of the AJ ridge, whereas in surveys 2 and 3, these maxima are present with values of 0.45 and 0.4 in the northwestern part of the gyre, coincident with the diffluent isopycnals upstream the AJ ridge. The large meridional velocity shear is related to the difference between the speed of the AJ and the slow waters in the north (Viúdez et al. 1996a). The vertical vorticity $\zeta$ in the AJ is larger in surveys 2 and 3 than in 1 . This is related to the increase of horizontal shear due to the larger AJ velocities in the last two surveys. The core and the surrounding ring of the WAG may be distinguished using the scalar invariant $Q=\left(|\boldsymbol{\Omega}|^{2}-|\mathbf{S}|^{2}\right) / 2$, where $\boldsymbol{\Omega}=\left(\boldsymbol{\nabla} \mathbf{u}-\boldsymbol{\nabla} \mathbf{u}^{\mathrm{T}}\right) / 2$ and $\mathbf{S}=\left(\boldsymbol{\nabla} \mathbf{u}+\boldsymbol{\nabla} \mathbf{u}^{\mathrm{T}}\right) / 2$ are the 

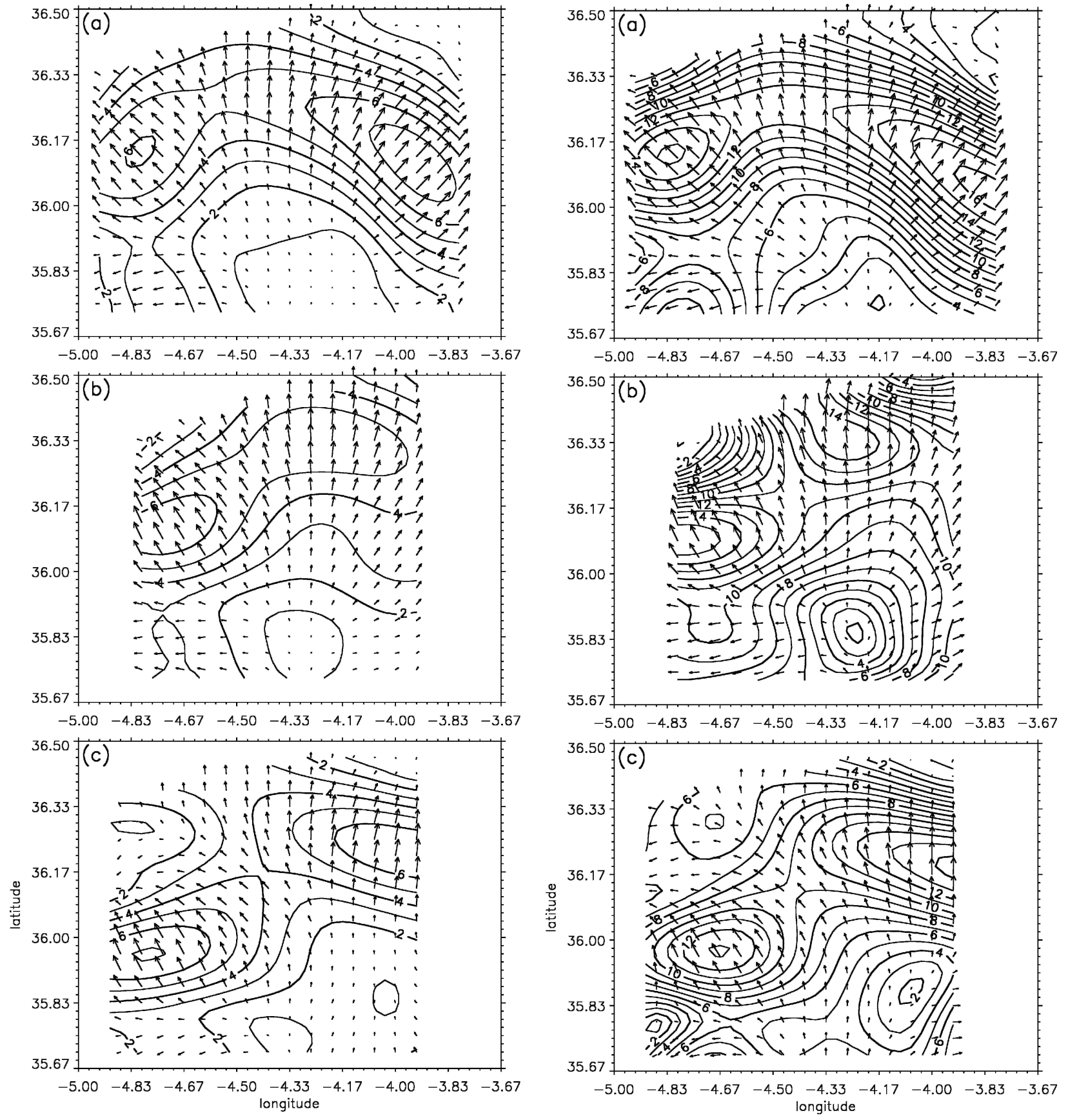

FIG. 7. The horizontal buoyancy gradient $\nabla_{h} \varrho$ for the three surveys. Isolines indicate the magnitude $\left|\nabla_{h} \varrho\right|\left(\Delta=10^{-7} \mathrm{~s}^{-2}, z=\right.$ $-100 \mathrm{~m})$.

antisymmetric and symmetric parts of the velocity gradient tensor $\nabla u$, respectively (Hunt et al. 1988). The core is characterized by values $Q>0$. For horizontal flows this criterion is $Q=\operatorname{det}\left\{\nabla_{h} \mathbf{u}_{h}\right\}=u_{x} v_{y}-u_{y} v_{x}=$ $-\left(u_{x}\right)^{2}-v_{x} u_{y}>0$, which has been used to detect eddy cores from satellite sea level anomaly in the western Mediterranean (Isern-Fontanet et al. 2003). This ap-

FIG. 8. Term $f \zeta_{\mathrm{ph}}+\nabla_{h} \varrho$ for the three surveys. Isolines indicate the magnitude with $\Delta=10^{-7} \mathrm{~s}^{-2}(z=-100 \mathrm{~m})$.

proach based on $Q$ is equivalent to the use of the kinematical vorticity number $\mathcal{W} \equiv|\mathbf{\Omega}| / \mathbf{S} \mid$ (Truesdell 1953, 1954; Viúdez et al. 1998b analyzes $\mathcal{W}$ in the Alboran Sea). The limit of the WAG core, via the $Q$ criterion, is approximately coincident with the contour of maximum speed (Fig. 4). The small-scale cyclonic eddies referred to in section $2 \mathrm{~b}$ are also identified by the contour $Q=0$. 

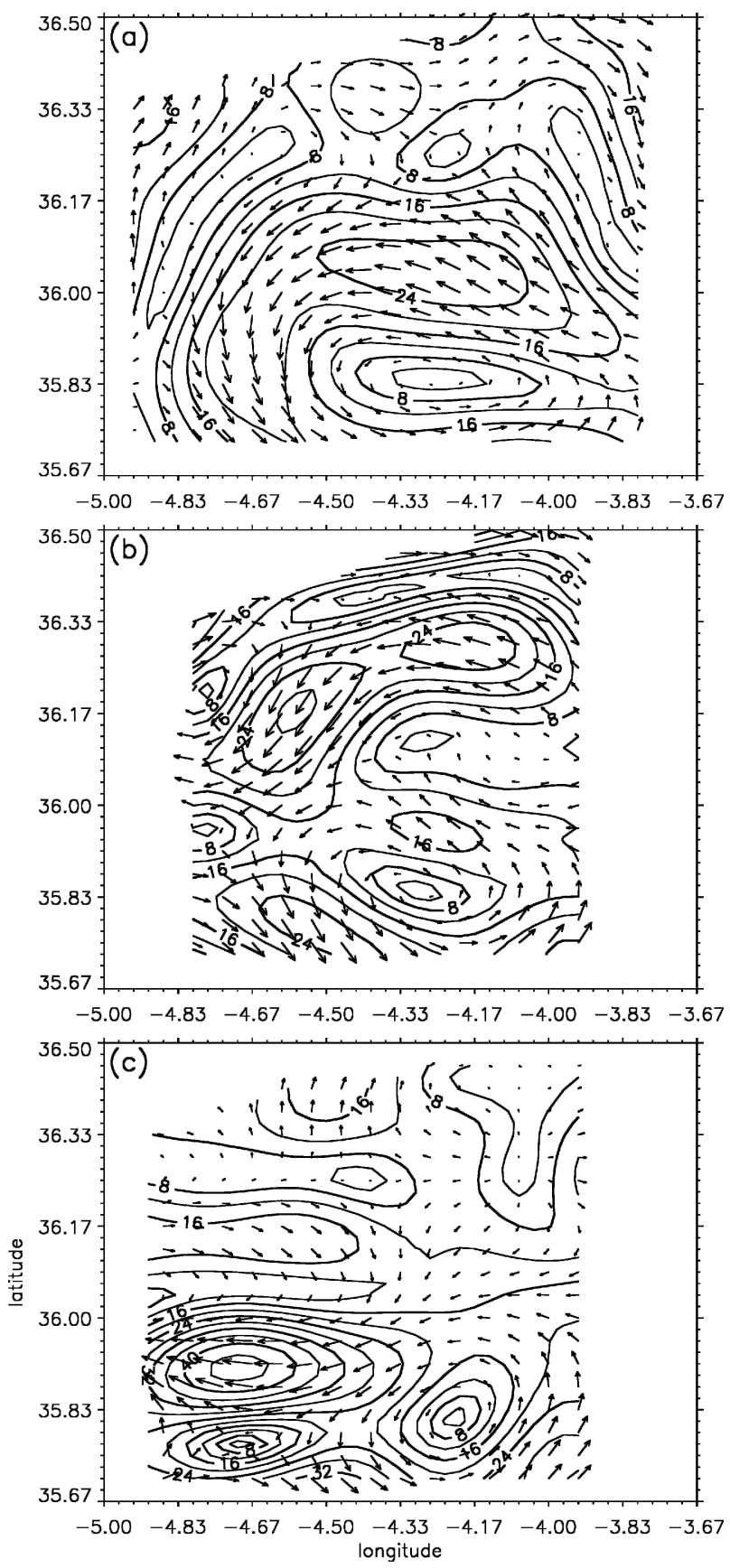

FIG. 9. The horizontal Laplacian $\nabla_{h}^{2} \mathbf{u}_{h}$ for the three surveys. Isolines indicate the magnitude $\left|\nabla_{h}^{2} \mathbf{u}_{h}\right|\left(\Delta=4 \times 10^{-10} \mathrm{~m}^{-1} \mathrm{~s}^{-1}, z\right.$ $=100 \mathrm{~m}$ ).

\section{Analysis of the $\omega$ equation}

\section{a. The generalized $\omega$ equation}

For completeness and definition of the terms used later we include a brief derivation of the generalized $\omega$ equation for inviscid, isentropic, and Boussinesq flow on the $f$ plane (Viúdez et al. 1996c). Vector components

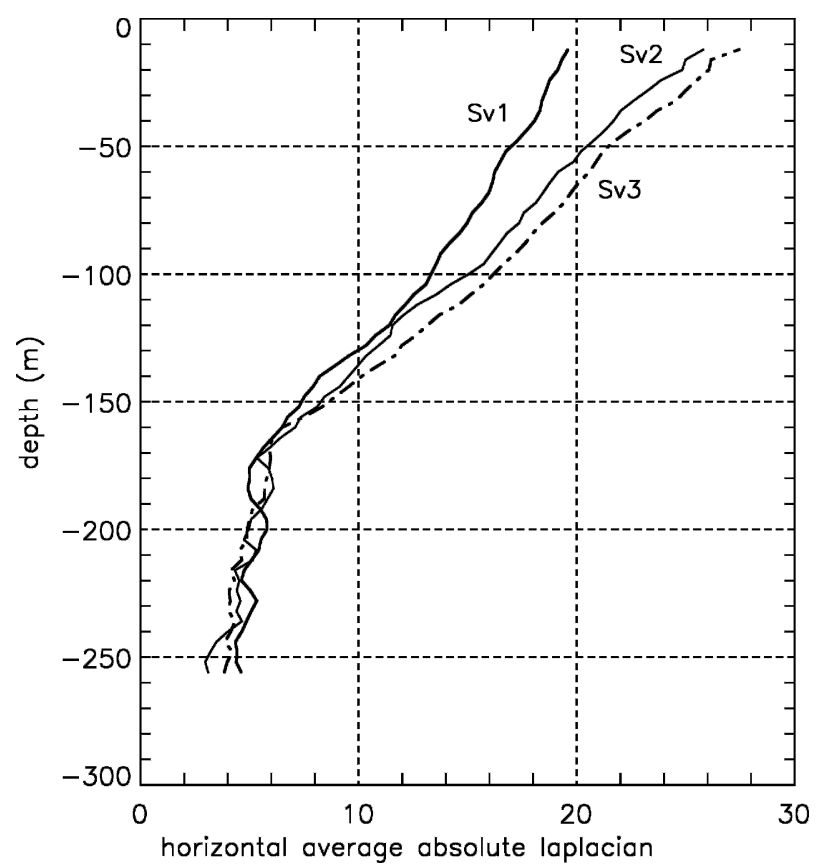

FIG. 10. Horizontal average of $\left|\nabla_{h}^{2} \mathbf{u}_{h}\right|$ as a function of depth for the three surveys $\left(10^{-10} \mathrm{~m}^{-1} \mathrm{~s}^{-1}\right.$; the average includes the grid points with $\left.\left|\mathbf{u}_{h}\right|>5 \mathrm{~cm} \mathrm{~s}^{-1}\right)$.

here refer always to a Cartesian vector basis. Let $\mathbf{u}_{h}^{g} \equiv$ $-\alpha_{0} f^{-1} \mathbf{k} \times \nabla_{h} \phi$ and $\mathbf{u}_{h}^{\prime} \equiv \mathbf{u}_{h}-\mathbf{u}_{h}^{g}$ be the geostrophic and ageostrophic horizontal velocities, respectively. Above $f \equiv 2 \Omega \sin \vartheta_{0}$ is the Coriolis parameter at the mean latitude $\vartheta_{0}, \alpha_{0} \equiv 1 / \rho_{0}$, where $\rho_{0}$ is the mean density, $\phi$ is the geopotential, and $\mathbf{k}$ is the unit vertical vector. The horizontal momentum, volume conservation, density conservation, and thermal wind equations are

$$
\begin{aligned}
d \mathbf{u}_{h} / d t+f \mathbf{k} \times \mathbf{u}_{h}^{\prime} & =\mathbf{0}, \\
\boldsymbol{\nabla} \cdot \mathbf{u} & =0, \\
d \varrho / d t & =0, \quad \text { and } \\
f \mathbf{k} \times \mathbf{u}_{h z}^{g} & =\nabla_{h} \varrho,
\end{aligned}
$$

where $\varrho=\rho g \alpha_{0}$ is the buoyancy, and $g$ is the acceleration due to gravity. The vertical component of the curl of (1) yields the vertical vorticity equation:

$$
d \zeta / d t=(f+\zeta) w_{z}+\zeta_{\mathrm{ph}} \cdot \nabla_{h} w,
$$

where $\zeta_{\text {ph }} \equiv \mathbf{k} \times \mathbf{u}_{h z}=-v_{z} \mathbf{i}+u_{z} \mathbf{j}$ is the horizontal pseudovorticity. From (3) we obtain the rate of change of $\nabla_{h} \varrho$ :

$$
d \nabla_{h} \varrho / d t=-\nabla_{h} \mathbf{u}_{h} \cdot \nabla_{h} \varrho-\varrho_{z} \nabla_{h} w
$$



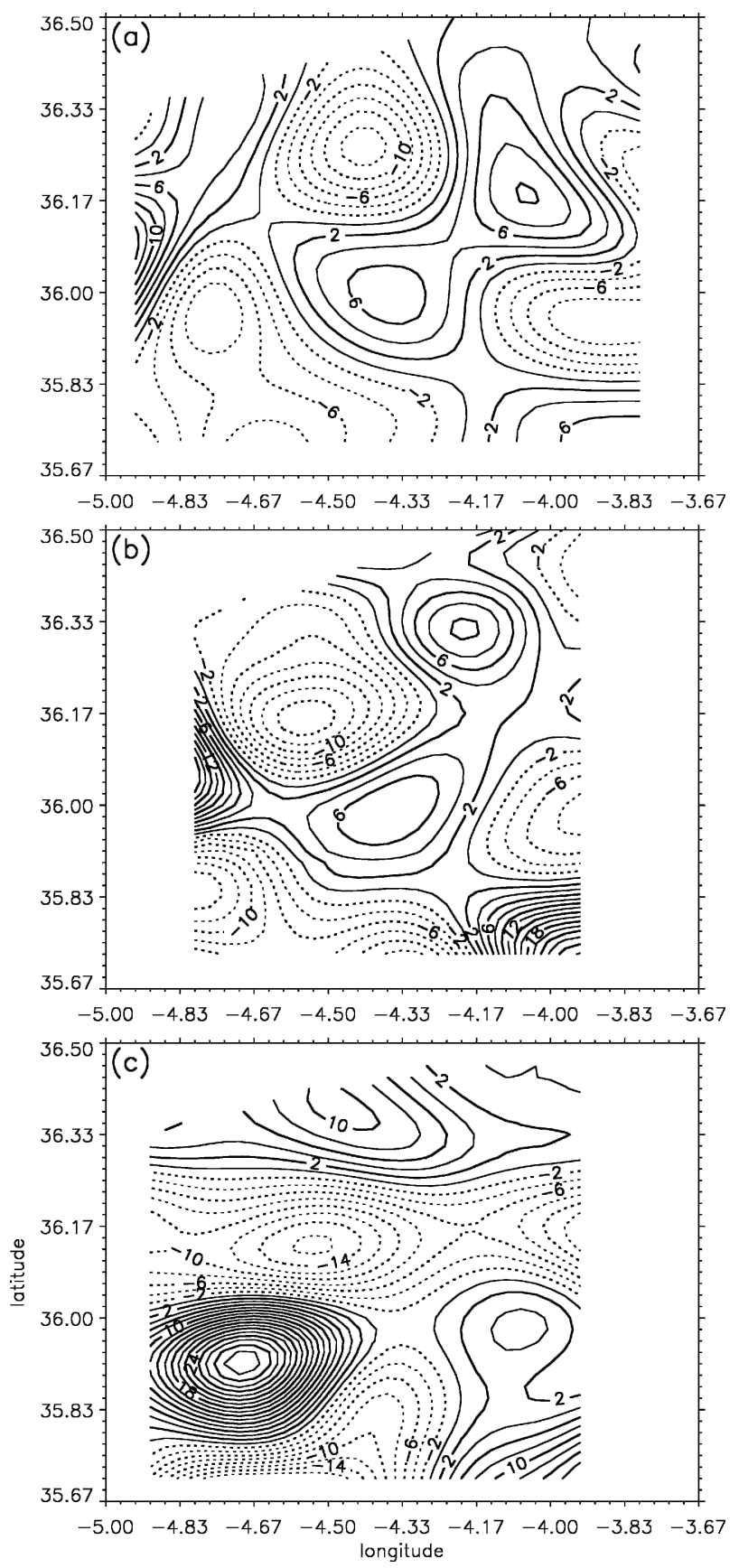

FIG. 11. Term $\left(f \zeta_{\text {ph }}+\nabla_{h} \varrho\right) \cdot \nabla_{h}^{2} \mathbf{u}_{h}$ for the three surveys $(\Delta=2$ $\left.\times 10^{-16} \mathrm{~m}^{-1} \mathrm{~s}^{-3}, z=-100 \mathrm{~m}\right)$.

The horizontal divergence of (6) yields the rate of change of the differential geostrophic vorticity $\zeta_{z}^{g}=$ $-f^{-1} \nabla_{h}^{2} \varrho$,

$$
\begin{aligned}
d \zeta_{z}^{g} / d t= & 2 f^{-1}\left[\nabla_{h} \mathbf{u}_{h}: \nabla_{h}\left(\nabla_{h} \varrho\right)+\nabla_{h} w \cdot \nabla_{h} \varrho_{z}\right] \\
& +f^{-1} \boldsymbol{\nabla} \varrho \cdot \nabla_{h}^{2} \mathbf{u}
\end{aligned}
$$

where $\mathbf{A}: \mathbf{B}=\Sigma \mathrm{A}_{i j} B_{i j}$ is the scalar "double dot" product of two dyadics $\mathbf{A}=\sum \mathbf{A}_{i j} \mathbf{e}_{i} \mathbf{e}_{j}$ and $\mathbf{B}=\sum B_{i j} \mathbf{e}_{i} \mathbf{e}_{j}$. The $\omega$ equation is the equation for the rate of change of the differential ageostrophic vorticity $\zeta_{z}^{\prime}=\zeta_{z}-\zeta_{z}^{g}$, and is obtained from (5) and (7):

$$
\begin{aligned}
d \zeta_{z}^{\prime} / d t= & -f^{-1} \nabla_{h} \cdot\left[2 \mathbf{Q}_{h}+\varrho_{z} \nabla_{h} w\right]+(f+\zeta) w_{z z} \\
& +\zeta_{\mathrm{ph} z}^{\prime} \cdot \nabla_{h} w-\zeta_{\mathrm{ph}}^{\prime} \cdot \nabla_{h}^{2} \mathbf{u}_{h},
\end{aligned}
$$

where $\zeta_{\mathrm{ph}}^{\prime} \equiv \mathbf{k} \times \mathbf{u}_{h}^{\prime}=-\boldsymbol{v}_{z}^{\prime} \mathbf{i}+u_{z}^{\prime} \mathbf{j}$ is the horizontal ageostrophic pseudovorticity and

$$
\boldsymbol{\nabla}_{h} \cdot \mathbf{Q}_{h}=\nabla_{h} \mathbf{u}_{h}: \nabla_{h}\left(\nabla_{h} \varrho\right)+\nabla_{h} \varrho \cdot \nabla_{h}^{2} \mathbf{u}_{h},
$$

is the horizontal divergence of the horizontal frontogenetical vector, or generalized $\mathbf{Q}$ vector, $\mathbf{Q}_{h} \equiv$ $\nabla_{h} \mathbf{u}_{h} \cdot \nabla_{h} \varrho$.

\section{b. Approximate $\omega$ equation}

Neglecting in (8), (i) the material rate of change of $\zeta_{z}^{\prime}$, (ii) terms $\zeta_{\mathrm{phz}}^{\prime} \cdot \nabla_{h} w$ and $\boldsymbol{\nabla}_{h} \varrho_{z} \cdot \nabla_{h} w$, and (iii) the horizontal changes of $\varrho$, so that $\varrho_{z} \nabla_{h}^{2} w \simeq-N^{2} / f \nabla_{h}^{2} w$, where the squared background Brunt-Väisälä $N^{2}=\bar{N}^{2}(z)=$ $-g \alpha_{0} \overline{\rho_{z}}$, the generalized $\omega$ Eq. (8) is simplified (Viúdez and Dritschel 2004) to

$$
\begin{aligned}
N^{2} \nabla_{h}^{2} w+f(f+\zeta) w_{z z}= & \underbrace{\left(f \zeta_{\mathrm{ph}}+\nabla_{h} \varrho\right) \cdot \nabla_{h}^{2} \mathbf{u}_{h}}_{R_{1}} \\
& +\underbrace{2 \boldsymbol{\nabla}_{h} \mathbf{u}_{h}: \boldsymbol{\nabla}_{h}\left(\boldsymbol{\nabla}_{h} \varrho\right)}_{R_{2}},
\end{aligned}
$$

which can be solved for $w$ assuming that both $\mathbf{u}_{h}$ and $\varrho$ are known. Terms $R_{1}$ and $R_{2}$ contain the second derivatives of buoyancy and horizontal velocity, respectively. An analysis of $\zeta_{\mathrm{ph} z}^{g}=f^{-1} \nabla_{h} \varrho_{z}$ and $\zeta_{\mathrm{ph} z}^{\prime}$ using the dataset in the Alboran Sea showed that $\left|\zeta_{\mathrm{ph} z}^{\prime}\right|>\left|f^{-1} \nabla_{h} \varrho_{z}\right|$, and as a consequence $\boldsymbol{\nabla}_{h} \varrho_{z} \cdot \nabla_{h} w$ in (8) can be neglected, leading to the approximation $\boldsymbol{\nabla}_{h} \cdot\left(\varrho_{z} \boldsymbol{\nabla}_{h} w\right) \simeq \varrho_{z} \boldsymbol{\nabla}_{h}^{2} w$. Nevertheless, the term $\zeta_{\mathrm{ph} z}^{\prime} \cdot \nabla_{h} w$ is still much smaller than the largest terms in the rhs of (8) - for example, $2 \boldsymbol{\nabla}_{h} \cdot \boldsymbol{Q}_{h}$-and does not significantly contribute to the resulting $w$ (assumption ii above). Similarly, assumption iii has been justified in a sensitivity test, which showed that no significant differences in $w$ are found with regard to the choice of $N^{2}(x, y, z)$ or $\bar{N}^{2}(z)$ in the lhs of (9).

In terms of the $\mathbf{Q}$ vector, Eq. (9) is rewritten as

$$
N^{2} \nabla_{h}^{2} w+f(f+\zeta) w_{z z}=2 \nabla_{h} \cdot \mathbf{Q}_{h}+f \zeta_{\mathrm{ph}}^{\prime} \cdot \nabla_{h}^{2} \mathbf{u}_{h} .
$$



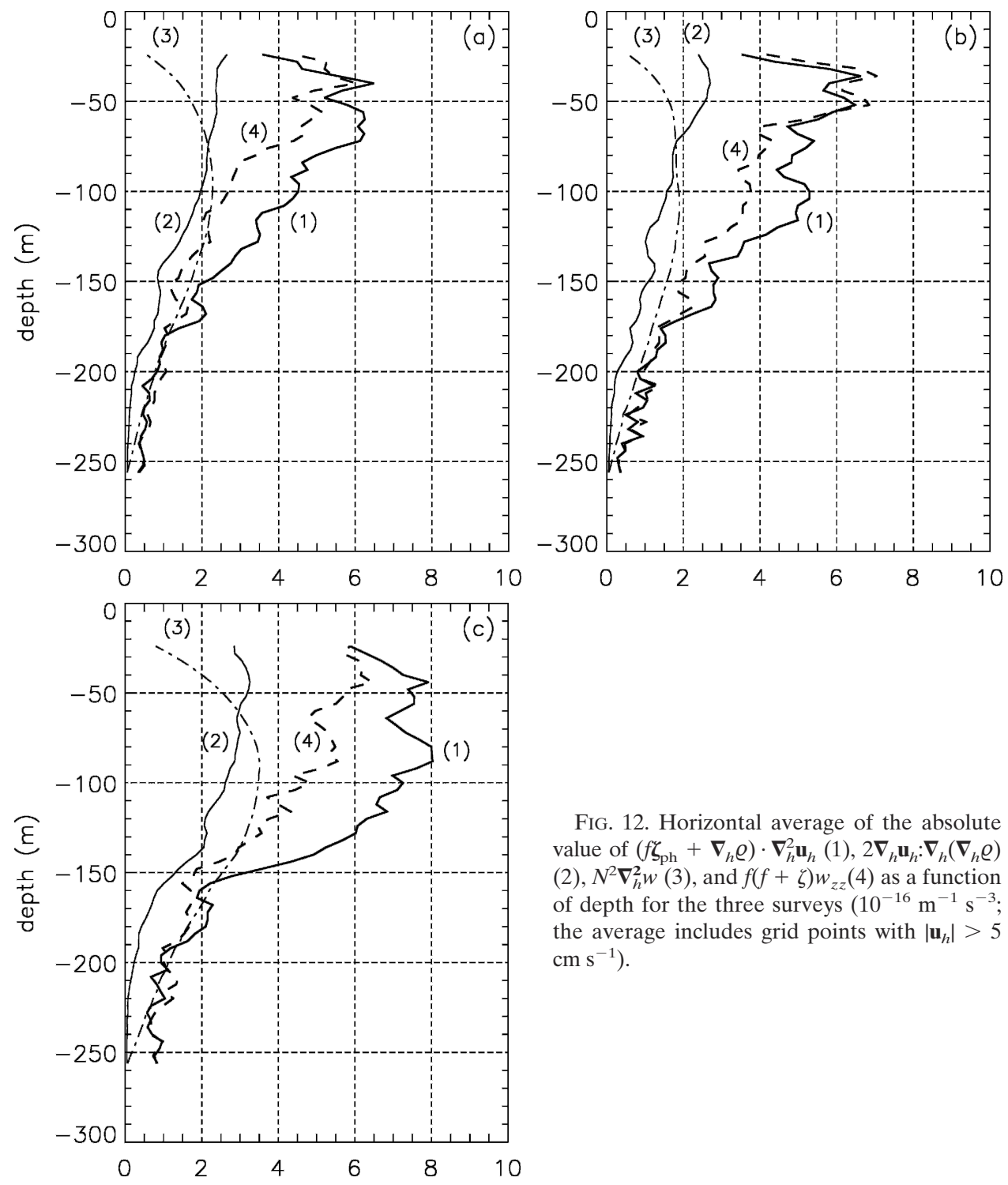

FIG. 12. Horizontal average of the absolute value of $\left(f \zeta_{\mathrm{ph}}+\nabla_{h} \varrho\right) \cdot \nabla_{h}^{2} \mathbf{u}_{h}(1), 2 \nabla_{h} \mathbf{u}_{h}: \nabla_{h}\left(\nabla_{h} \varrho\right)$ (2), $N^{2} \nabla_{h}^{2} w(3)$, and $f(f+\zeta) w_{z z}(4)$ as a function of depth for the three surveys $\left(10^{-16} \mathrm{~m}^{-1} \mathrm{~s}^{-3}\right.$; the average includes grid points with $\left|\mathbf{u}_{h}\right|>5$ $\mathrm{cm} \mathrm{s}^{-1}$ ).

The QG $\omega$ equation results as a particular case of (10) when the ageostrophic horizontal velocity gradients are neglected relative to the geostrophic ones $\left(\mathbf{Q}_{h} \rightarrow \mathbf{Q}_{h}^{g}\right.$, $\left.\zeta_{\mathrm{ph}}^{\prime} \rightarrow 0\right)$, and $|\zeta| \ll|f|$,

$$
N^{2} \nabla_{h}^{2} w^{q}+f^{2} w_{z z}^{q}=2 \nabla_{h} \cdot \mathbf{Q}_{h}^{g} .
$$

The different "forcing" in Eqs. (10) and (11) is due to the divergence of the ageostrophic vector $\mathbf{Q}_{h}^{\prime}$ and to the term $f \zeta_{\mathrm{ph}}^{\prime} \cdot \nabla_{h}^{2} \mathbf{u}_{h}$, both involving ageostrophic quantities. Therefore, for largely ageostrophic flows where the QG approximation fails, Eq. (9) is still valid.

Davies-Jones (1991) formulated a generalization of the QG $\omega$ equation similar to (11):

$$
N^{2} \nabla_{h}^{2} w+f^{2} w_{z z}=2 \nabla_{h} \cdot \hat{\mathbf{Q}}_{h},
$$

where the vector $2 \hat{\mathbf{Q}}_{h} \equiv \boldsymbol{\nabla}_{h} \mathbf{u}_{h} \cdot\left(f \zeta_{\mathrm{ph}}+\boldsymbol{\nabla}_{h} \varrho\right)$ is composed of the frontogenetical vector $\mathbf{Q}_{h}$, plus a vortexstretching vector $f \boldsymbol{\nabla}_{h} \mathbf{u}_{h} \cdot \boldsymbol{\zeta}_{\mathrm{ph}}$. For comparison purposes we have used above $\hat{\mathbf{Q}}_{h}$ instead of the original $\mathbf{Q}_{h}^{*}=$ $f^{-1} \hat{\mathbf{Q}}_{h}$. Since, for any vector $\mathbf{a}_{h}$, we have $\boldsymbol{\nabla}_{h} \cdot\left(\boldsymbol{\nabla}_{h} \mathbf{u}_{h} \cdot \mathbf{a}_{h}\right)$ $=\nabla_{h} \mathbf{u}_{h}: \nabla_{h} \mathbf{a}_{h}+\mathbf{a}_{h} \cdot \nabla_{h}^{2} \mathbf{u}_{h}$, Eqs. (9) and (12) differ in that (12) has the additional term $f \boldsymbol{\nabla}_{h} \mathbf{u}_{h}: \boldsymbol{\nabla}_{h} \boldsymbol{\zeta}_{\mathrm{ph}}^{\prime}$ in the rhs, and does not include $f \zeta w_{z z}$ in the lhs. Vector $\hat{\mathbf{Q}}_{h}$ reduces to $\mathbf{Q}_{h}^{g}$ when horizontal and vertical velocity gradients are geostrophic: $\nabla_{h} \mathbf{u}_{h} \rightarrow \nabla_{h} \mathbf{u}_{h}^{g}$ and $f \zeta_{\mathrm{ph}} \rightarrow \nabla_{h} \varrho$.

\section{c. Analysis of terms in the $\omega$ equation}

Next we carry out the analysis of the terms in the $\omega$ Eq. (9) for the three surveys in the Alboran Sea. 

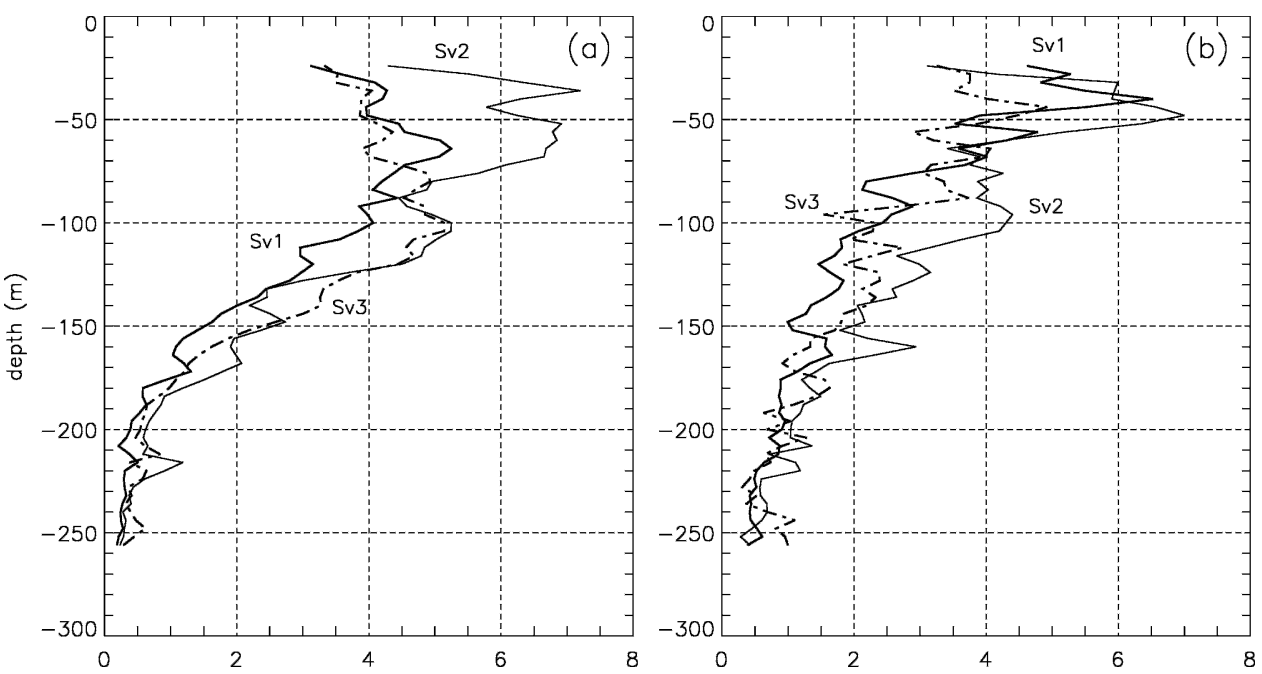

FIG. 13. Horizontal average of (a) $|2 f \partial| \mathbf{u}_{h}\left|/ \partial z \mathbf{s}_{h} \cdot \nabla_{h} \zeta\right|$ and (b) $\left|2 f \mathbf{u}_{h} \Theta_{Z} \mathbf{n}_{h} \cdot \nabla_{h} \zeta\right|$ as a function of depth for the three surveys $\left(10^{-16} \mathrm{~m} \mathrm{~s}^{-1}\right.$; the average includes the grid points with $\left.\left|\mathbf{u}_{h}\right|>5 \mathrm{~cm} \mathrm{~s}^{-1}\right)$.

\section{1) Pseudovorticity}

The horizontal pseudovorticity $\boldsymbol{\zeta}_{\text {ph }}$ can be equally interpreted as the horizontal vorticity of the horizontal three-dimensional flow, and as the anticlockwise rotation of the vertical shear,

$$
\boldsymbol{\zeta}_{\mathrm{ph}}=\left(\boldsymbol{\nabla} \times \mathbf{u}_{h}\right)_{h}=\mathbf{k} \times \mathbf{u}_{h z}=\left(-\boldsymbol{v}_{z}, u_{z}\right) .
$$

The magnitude of the pseudovorticity term in (9) $f \zeta_{\mathrm{ph}}$ (Fig. 5) reached relative maxima of $9-10\left(\times 10^{-7} \mathrm{~s}^{-2}\right.$, at $z=-100 \mathrm{~m})$ in surveys 1 and 2 , and about $6-8\left(\times 10^{-7}\right.$ $\mathrm{s}^{-2}$ ) in survey 3, mainly located in the AJ. Relative minima of $1-2\left(\times 10^{-7} \mathrm{~s}^{-2}\right)$ are found in the core of the WAG and in the northern boundary of the AJ.

In the reference frame defined by the unit vectors tangential and normal to the horizontal velocity, $\mathbf{s}_{h} \equiv$ $\mathbf{u}_{h} /\left|\mathbf{u}_{h}\right|$ and $\mathbf{n}_{h} \equiv \mathbf{k} \times \mathbf{u}_{h}$, respectively, the vertical shear may be decomposed into the streamwise and crossstream components,

$$
\mathbf{u}_{h z}=\left|\mathbf{u}_{h}\right|_{z} \mathbf{s}_{h}+\left|\mathbf{u}_{h}\right| \Theta_{Z} \mathbf{n}_{h},
$$

where $\left|\mathbf{u}_{h}\right|_{z}=\mathbf{s}_{h} \cdot \mathbf{u}_{h z}$ is the vertical shear speed, and $\Theta_{Z}$ is the backing/veering of the horizontal current, $\left|\mathbf{u}_{h}\right| \Theta_{Z}$ $=\mathbf{n}_{h} \cdot \mathbf{u}_{h z}$. The horizontally averaged profiles (Fig. 6) show that the streamwise component $\left\langle|\partial| \mathbf{u}_{h}|/ \partial z|\right\rangle_{H}$ (subscript $H$ indicates horizontal average) dominates over the crossstream component $\left\langle\left|\mathbf{u}_{h} \Theta_{Z}\right|\right\rangle_{H}$, the latter being approximately constant with depth. Thus, the vertical shear $\mathbf{u}_{h z}$ is dominantly in the same direction as $\mathbf{u}_{h}$, and since $\zeta_{\mathrm{ph}}=\mathbf{k} \times \mathbf{u}_{h z}$, the pseudovorticity is directed out of the core of the WAG. We will see below that the $\boldsymbol{\zeta}_{\mathrm{ph}}$ term in (9) is related to the advection of vertical vorticity by the vertical shear $\left(\mathbf{u}_{h z} \cdot \nabla_{h} \zeta\right)$, which provides an easy way to infer vertical motion from the horizontal velocity field (or from the geopotential or density isolines).

\section{2) Horizontal BUOyancy GRADient}

The horizontal buoyancy gradient or, equivalently, the horizontal geostrophic pseudovorticity times $f$,

$$
\nabla_{h} \varrho=f_{\mathrm{ph}}^{g}=f \mathbf{k} \times \mathbf{u}_{h z}^{g},
$$

is shown in Fig. 7 at $100 \mathrm{~m}$ for the three surveys. Maxima $\left|\nabla_{h} \varrho\right|$ of 5-7 $\left(\times 10^{-7} \mathrm{~s}^{-2}\right)$ are found in the AJ. The vector $\nabla_{h} \varrho$ is, like $\zeta_{\mathrm{ph}}$, directed out of the core of the WAG, although its magnitude is smaller than $\left|f \zeta_{\mathrm{ph}}\right|$ since, as we have mentioned above, the flow is mostly supergeostrophic. Minima $\left|\nabla_{h} \varrho\right|$ are located in the core of the WAG where isopycnals are flat.

\section{3) TERM $f \zeta_{\mathrm{ph}}+\nabla_{h} \varrho$}

Term $f \zeta_{\mathrm{ph}}+\nabla_{h} \varrho$ has a spatial distribution (Fig. 8) similar to the pseudovorticity term, which implies that $\left|f \zeta_{\mathrm{ph}}\right|$ predominates over $\left|\boldsymbol{\nabla}_{h} \varrho\right|$. Vectors $\boldsymbol{\nabla}_{h} \varrho$ and $f \zeta_{\mathrm{ph}}$ are approximately in the same direction. Maxima of $\mid f \zeta_{\mathrm{ph}}+$ $\nabla_{h} \varrho \mid$ occurs at about $100-110 \mathrm{~m}$, the approximate depth at which $\left|\mathbf{u}_{h z}\right|$ reaches maximum values. At $100 \mathrm{~m}$, maximum values of $\left|f \zeta_{\mathrm{ph}}+\nabla_{h} \varrho\right|$ are 16,15 , and $14\left(\times 10^{-7}\right.$ $\mathrm{s}^{-2}$ ) in surveys 1,2 , and 3 , respectively. The component of this term in the direction of $\nabla_{h}^{2} \mathbf{u}_{h}$ (analyzed next) is the most important term in the $\omega$ Eq. (9). 


\section{4) LAPLACIAN OF $\mathbf{u}_{h}$}

The Laplacian of the horizontal velocity, $\nabla_{h}^{2} \mathbf{u}_{h}$, may be decomposed as

$$
\begin{aligned}
\nabla_{h}^{2} \mathbf{u}_{h} & =k \times \nabla_{h} \zeta+\nabla_{h}\left(\nabla_{h} \cdot \mathbf{u}_{h}\right)=\mathbf{k} \times \nabla_{h} \zeta-\nabla_{h} w_{z} \\
& \simeq \mathbf{k} \times \nabla_{h} \zeta .
\end{aligned}
$$

Thus, neglecting $\boldsymbol{\nabla}_{h} w_{z}$, the Laplacian $\boldsymbol{\nabla}_{h}^{2} \mathbf{u}_{h}$ can be interpreted as an anticlockwise rotation of $\boldsymbol{\nabla}_{h} \zeta$. Consequently, the vector $\nabla_{h}^{2} \mathbf{u}_{h}$ (Fig. 9) is approximately directed opposite to $\mathbf{u}_{h}$, and its extrema coincide with the extrema of $\zeta$.

Relative minima of $\nabla_{h}^{2} \mathbf{u}_{h}$ reaching $6-8\left(\times 10^{-10} \mathrm{~m}^{-1}\right.$ $\mathrm{s}^{-1}$ ) in the three surveys, are located in the core of the WAG and in the northern boundary of the AJ, approximately above the isopycnal $\sigma_{\theta}=28.2$. In survey 1 , when the AJ-WAG system was well developed, absolute maximum values of $24\left(\times 10^{-10} \mathrm{~m}^{-1} \mathrm{~s}^{-1}\right)$ are found in the northern part of the WAG (Fig. 9), associated with the large gradients of $\zeta$ (line $Q=0$ in Fig. 4). In surveys 2 and 3 , the absolute maxima ( 28 and $44 \times 10^{-10} \mathrm{~m}^{-1}$ $\mathrm{s}^{-1}$, respectively) are shifted westward, because of the fast AJ inflow that increases the horizontal gradient of $\zeta$. This enhancement of $\zeta$ in the upper layer in surveys 2 and 3 is also identified by the high values of the horizontally averaged $\nabla_{h}^{2} \mathbf{u}_{h}$ (Fig. 10). An analysis of the errors in the field $\nabla_{h}^{2} \mathbf{u}_{h}$ is given in the appendix. The Laplacian of the geostrophic velocity $\nabla_{h}^{2} \mathbf{u}_{h}^{g}$ (not shown) exhibited important differences relative to $\nabla_{h}^{2} \mathbf{u}_{h}$, so that non-QG effects in $\omega$ are expected to emerge through this term in the solution of the $\omega$ Eq. (9).

\section{5) TERM $\left(f \zeta_{\mathrm{ph}}+\nabla_{h} \varrho\right) \cdot \nabla_{h}^{2} \mathbf{u}_{h}$}

From (13) and (15) the term $\left(f \zeta_{\mathrm{ph}}+\nabla_{h} \varrho\right) \cdot \nabla_{h}^{2} \mathbf{u}_{h}\left[R_{1}\right.$ in (9)] can be approximately expressed as the scalar product of $2 f \mathbf{u}_{h z}$ with $\boldsymbol{\nabla}_{h} \zeta$,

$$
\begin{aligned}
\left(f \zeta_{\mathrm{ph}}+\nabla_{h} \varrho\right) \cdot \nabla_{h}^{2} \mathbf{u}_{h} & =\left(2 f \zeta_{\mathrm{ph}}-f \zeta_{\mathrm{ph}}^{\prime}\right) \cdot \nabla_{h}^{2} \mathbf{u}_{h} \\
& \simeq 2 f\left(k \times \mathbf{u}_{h z}\right) \cdot\left(k \times \nabla_{h} \zeta\right) \\
& =2 f \mathbf{u}_{h z} \cdot \nabla_{h} \zeta
\end{aligned}
$$

and interpreted as the spatial change of $\zeta$ in the direction of $\mathbf{u}_{h z}$ (times $\left.2 f\left|\mathbf{u}_{h z}\right|\right)$. To the same degree of approximation it may be interpreted also as $2 f \mathbf{u}_{h z}^{g} \cdot \nabla_{h} \zeta$.

Absolute maxima of $R_{1}$ (Fig. 11) reach $32\left(\times 10^{-16}\right.$ $\mathrm{m}^{-1} \mathrm{~s}^{-3}$ ) in survey 3 because of the large values of $f \zeta_{\mathrm{ph}}$ $+\nabla_{h} \varrho$ (Fig. 8) and the absolute maxima of $\boldsymbol{\nabla}_{h}^{2} \mathbf{u}_{h}$ (Fig. 9). Horizontally averaged values of $R_{1}$ are given in Fig. 12. This term is the most important one in the $\omega$ Eq. (9), reaching in survey 3 the largest average value of 8 $\left(\times 10^{-16} \mathrm{~m}^{-1} \mathrm{~s}^{-3}\right)$ at $80-90 \mathrm{~m}$.
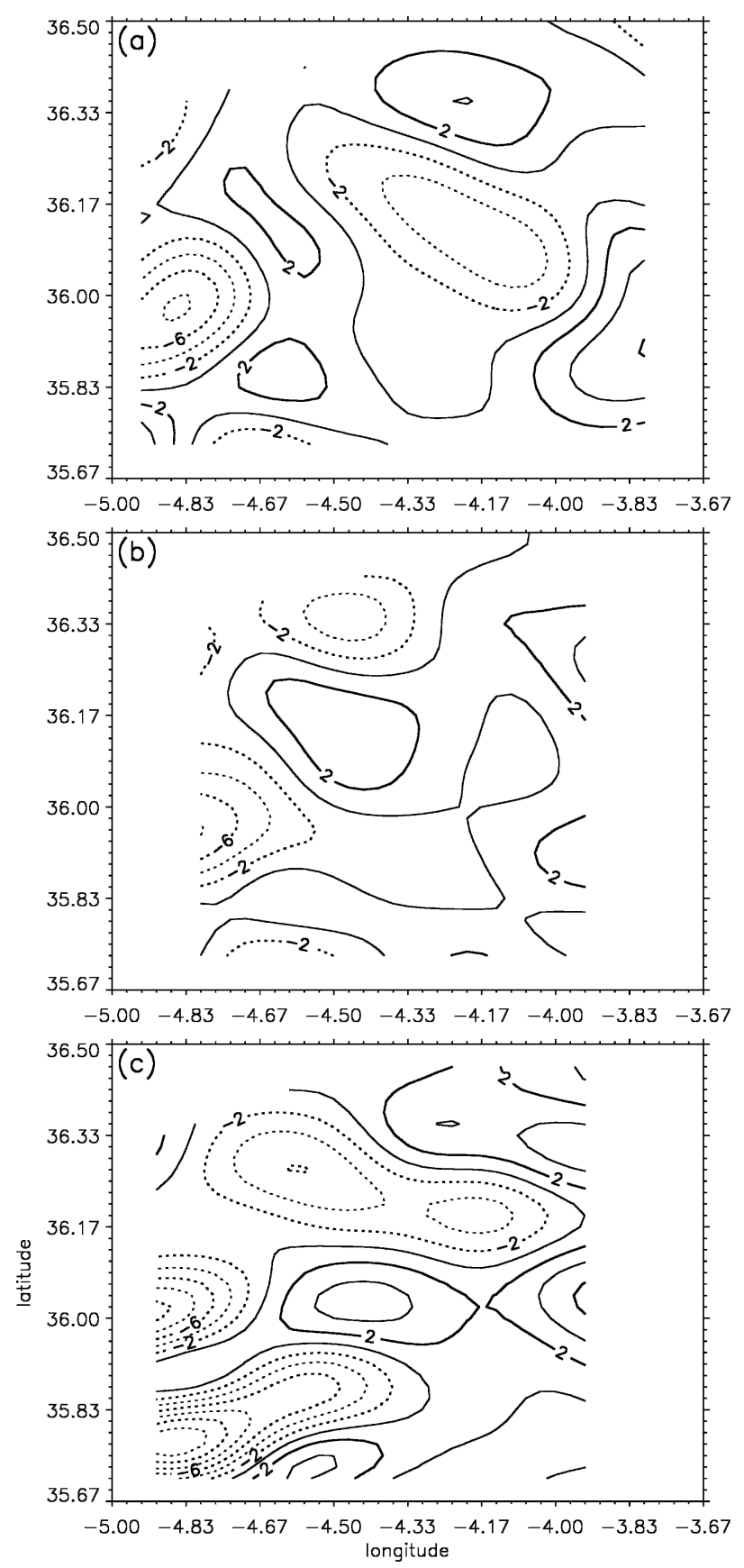

FIG. 14. Term $2 \boldsymbol{\nabla}_{h} \mathbf{u}_{h}: \nabla_{h}\left(\nabla_{h} \varrho\right)$ for the three surveys $(\Delta=2 \times$ $\left.10^{-16} \mathrm{~m}^{-1} \mathrm{~s}^{-3}, z=-100 \mathrm{~m}\right)$.

Using (14), term $\mathbf{u}_{h z} \cdot \nabla_{h} \zeta$ in (17) can be decomposed into two contributions from the streamwise and crossstream vertical shear,

$$
\mathbf{u}_{h z} \cdot \nabla_{h} \zeta=\left|\mathbf{u}_{h}\right|_{z} \mathbf{s}_{h} \cdot \nabla_{h} \zeta+\left|\mathbf{u}_{h}\right| \Theta_{Z} \mathbf{n}_{h} \cdot \nabla_{h} \zeta .
$$

Both average streamwise and cross-stream quantities, $\left\langle|\partial| \mathbf{u}_{h}\left|/ \partial z \mathbf{s}_{h} \cdot \nabla \zeta\right|\right\rangle_{H}$ and $\left\langle\left|\mathbf{u}_{h} \Theta_{Z} \mathbf{n}_{h} \cdot \nabla_{h} \zeta\right|\right\rangle_{H}$, contribute 

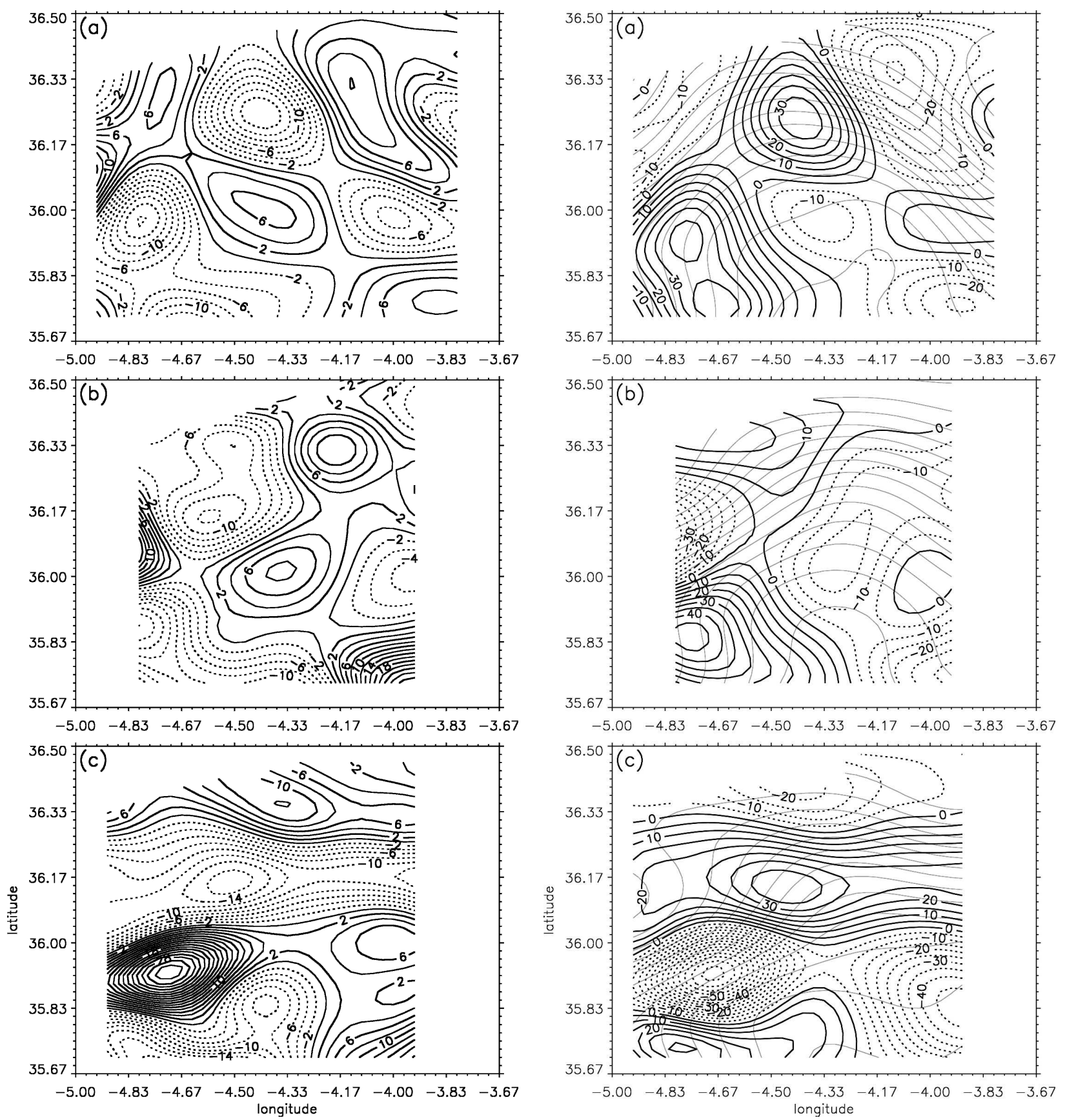

FIG. 15. Term $2 \boldsymbol{\nabla}_{h} \mathbf{u}_{h}: \nabla_{h}\left(\nabla_{h} \varrho\right)+\left(f \zeta_{\text {ph }}+\nabla_{h} \varrho\right) \cdot \nabla_{h}^{2} \mathbf{u}_{h}$ for the three surveys $\left(\Delta=2 \times 10^{-16} \mathrm{~m}^{-1} \mathrm{~s}^{-3}, z=-100 \mathrm{~m}\right)$.

equally to $\left\langle\left|\mathbf{u}_{h z} \cdot \nabla_{h} \zeta\right|\right\rangle_{H}$ (Fig. 13) despite the fact that, as we have shown before, $\left\langle|\partial| \mathbf{u}_{h}|/ \partial z|\right\rangle_{H}$ is larger than $\left\langle\left|\mathbf{u}_{h} \Theta_{Z}\right|\right\rangle_{H}$ (Fig. 6). This is because the cross-stream gradients of $\zeta$ are larger than the streamwise gradients in the AJ-WAG system.

In the advective (non- $\mathbf{Q}$ vector) generalized $\omega$ equation (Pauley and Nieman 1992), and in a similar way in its QG analog, the forcing of $w$ is interpreted in terms

FIG. 16. Vertical velocity $w\left(\Delta=5 \times 10^{-5} \mathrm{~m} \mathrm{~s}^{-1}, z=-100 \mathrm{~m}\right)$ and potential density anomaly $\left(\sigma_{\theta}\right.$, continuous unlabeled isolines) for the three surveys.

of $\boldsymbol{\nabla}_{h}^{2}\left(\mathbf{u}_{h} \cdot \nabla_{h} \varrho\right)$ plus $\left(\mathbf{u}_{h} \cdot \nabla_{h} \zeta\right)_{z}$, which apparently relates $w$ with the advection of $\zeta$ by the total current. Despite the well-known cancellation of the term $\mathbf{u}_{h} \cdot \boldsymbol{\nabla}_{h} \zeta_{z}^{g}$, this advective interpretation correctly predicts downward (upward) motion upstream (downstream) of geopotential troughs (and the opposite for geopotential ridges). Relation (17), together with the 

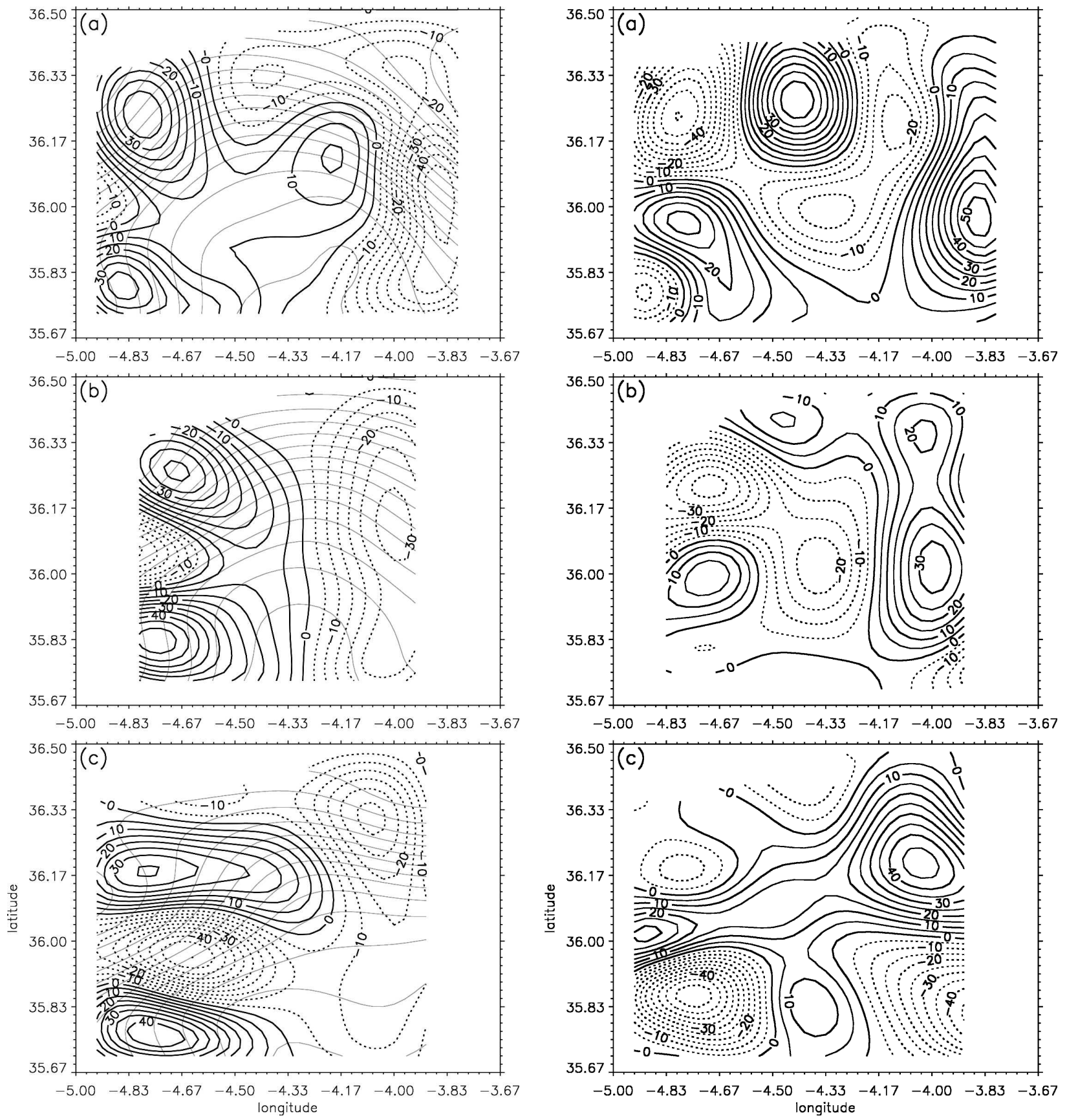

FIG. 17. The QG vertical velocity $w^{q}\left(\Delta=5 \times 10^{-5} \mathrm{~m} \mathrm{~s}^{-1}, z=\right.$ $-100 \mathrm{~m}$ ) and $\sigma_{\theta}$ (continuous unlabeled isolines) for the three surveys.

importance of this term, suggests that the success of the advective interpretation is based on the advection of $\zeta$, not by the total current $\mathbf{u}_{h}$, but by the shear, or differential current $\mathbf{u}_{h z}$.

\section{6) TERm $2 \nabla_{h} \mathbf{u}_{h}: \nabla_{h}\left(\nabla_{h} \varrho\right)$}

The term $2 \nabla_{h} \mathbf{u}_{h}: \nabla_{h}\left(\nabla_{h} \varrho\right)\left[R_{2}\right.$ in (9)] may be interpreted as a measure of the correlation between the spa-

FIG. 18. The difference $w-w^{q}$ for the three surveys $(\Delta=5 \times$ $10^{-5} \mathrm{~m} \mathrm{~s}^{-1}, z=100 \mathrm{~m}$ ).

tial changes of $\mathbf{u}_{h}$ and $\boldsymbol{\nabla}_{h} \varrho$. This term (Fig. 14) reaches maximum values of $4-6\left(\times 10^{-16} \mathrm{~m}^{-1} \mathrm{~s}^{-3}\right)$. Minima reach $-8\left(\times 10^{-16} \mathrm{~m}^{-1} \mathrm{~s}^{-3}\right)$ in surveys 1 and 2 , whereas the largest negative values (smaller than $-12 \times 10^{-16}$ $\mathrm{m}^{-1} \mathrm{~s}^{-3}$ ) are found in survey 3 . The extrema are located on the western part of the density front, where the AJ impinges on the WAG. Term $R_{2}$ is smaller than $R_{1}$ (Fig. 11 ), though both terms are of the same order of mag- 

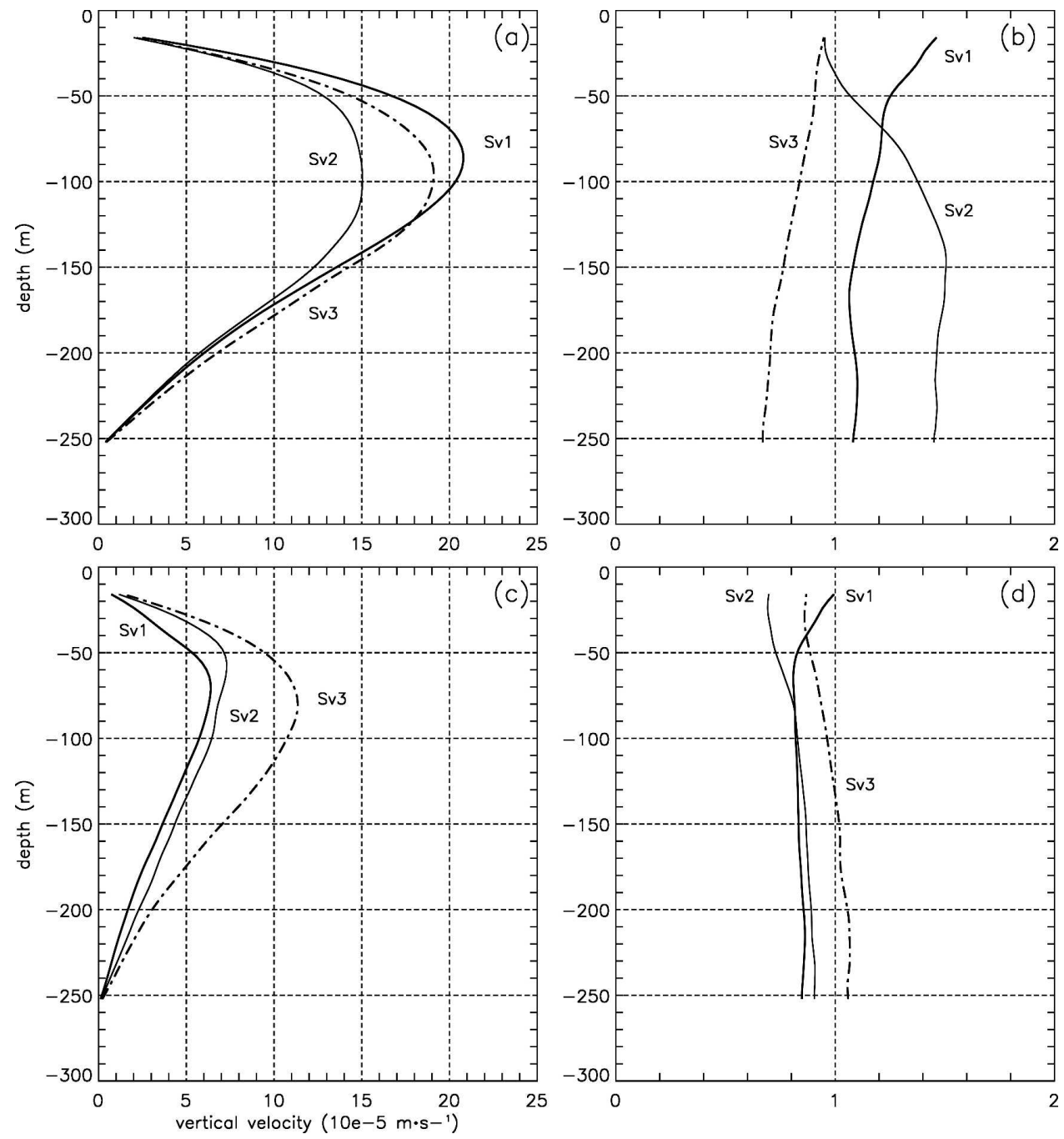

FIG. 19. The horizontally averaged rms difference between $w^{q}$ and $w$ as a function of depth for the three surveys: (a) $\left[n^{-1} \sum_{i, j}\left(w_{i, j}-w_{i, j}^{q}\right)^{2}\right]^{1 / 2}\left(10^{-5} \mathrm{~m} \mathrm{~s}^{-1}\right.$, where $n=41 \times 41 \times 61$ is the number of data points); (b) $\left\langle w^{q} / w\right\rangle_{H}$; (c), (d) as in (a) and (b), respectively, but for the vertical velocity resulting from including $2 \nabla_{h} \cdot \mathbf{Q}_{h}^{\prime}$ on the rhs of the QG $\omega$ Eq. (11).

nitude. On average, $R_{2}$ is $1 / 3-1 / 4$ of $R_{1}$ (Fig. 12), the latter term being largely responsible for the rhs of (9).

7) THE RHS OF THE $\omega$ EQ. (9)

Term $R_{1}+R_{2}$ (Fig. 15) is broadly similar to $R_{1}$ (Fig. 11) having smaller, but noticeable, differences due to $R_{2}$ (Fig. 14). Absolute maxima reached $32\left(\times 10^{-16} \mathrm{~m}^{-1}\right.$ $\mathrm{s}^{-3}$, survey 3 , in the western part of the $\mathrm{AJ}$ ), and minima $-16\left(\times 10^{-16} \mathrm{~m}^{-1} \mathrm{~s}^{-3}\right.$, survey 2 , located where the AJ impinges on the WAG).

Having analyzed the distributions of the forcing terms in the rhs of the $\omega$ Eq. (9), we next obtain $w$ and describe the relative importance of the terms in the lhs.

\section{8) The Vertical Velocity $w$ AND teRms IN THE LHS OF THE $\omega$ EQUATION}

The elliptic, linear, with nonconstant coefficients, partial differential Eq. (9) was solved, with zero Dirichlet boundary conditions, using an iterative relaxation method (e.g., William et al. 1993, their chapter 17). The vertical velocity $w$ (Fig. 16) is of $O\left(10^{-4}\right)$ $\mathrm{m} \mathrm{s}^{-1}$; that is, it is four orders of magnitude smaller than $\left|\boldsymbol{u}_{h}\right|$, with extrema at a depth of 70-100 m.

An upwelling region develops over the southwestern part of the WAG, with maxima of 35,45 , and $30\left(\times 10^{-5}\right.$ $\mathrm{m} \mathrm{s}^{-1}$ ) in surveys 1,2 , and 3 , respectively. These changes in $w$ seem to be associated to the southward displacement of the AJ. Another upwelling region is 

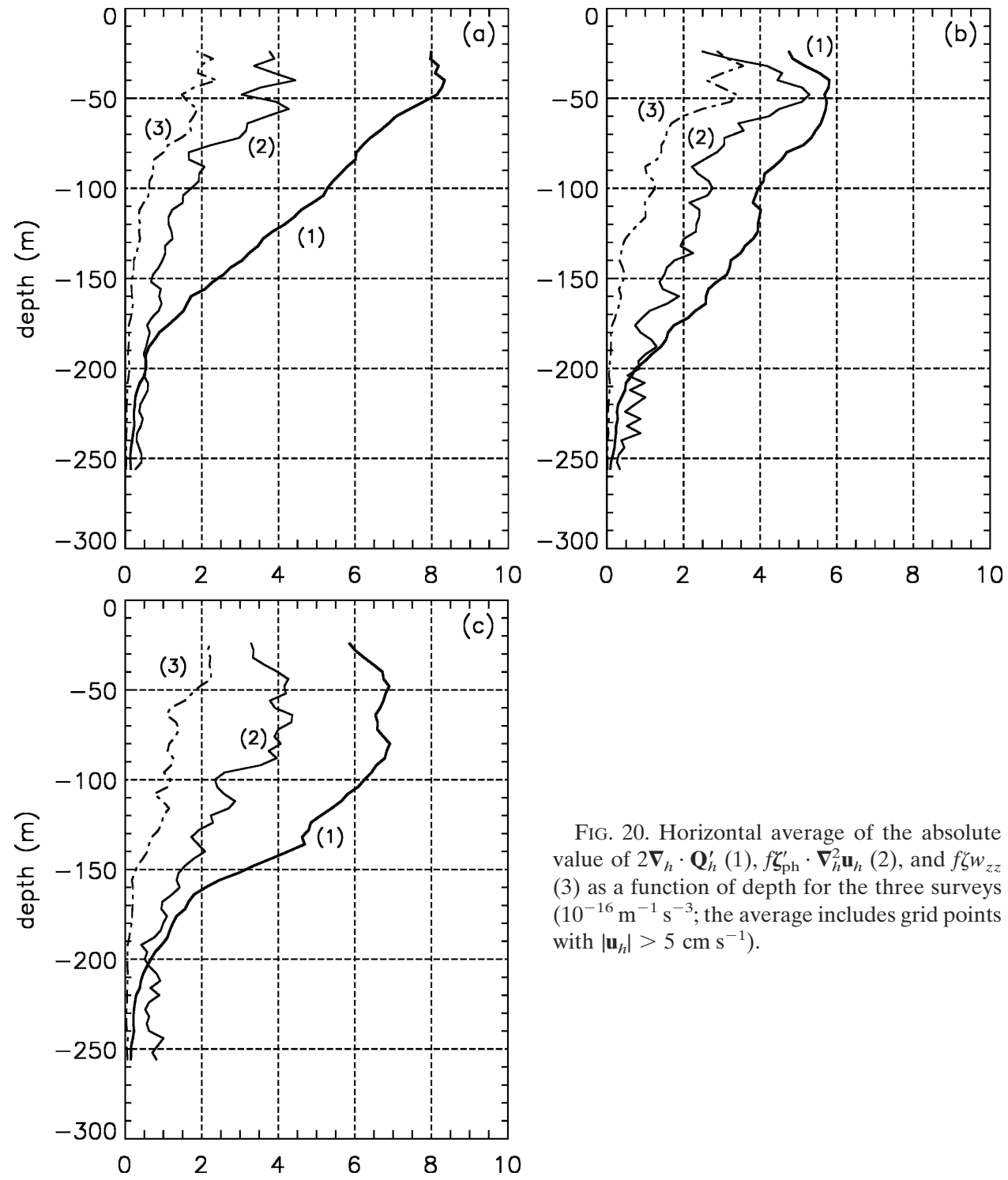

FIG. 20. Horizontal average of the absolute value of $2 \boldsymbol{\nabla}_{h} \cdot \mathbf{Q}_{h}^{\prime}(1), f \zeta_{\mathrm{ph}}^{\prime} \cdot \boldsymbol{\nabla}_{h}^{2} \mathbf{u}_{h}(2)$, and $f \zeta w_{z z}$ (3) as a function of depth for the three surveys $\left(10^{-16} \mathrm{~m}^{-1} \mathrm{~s}^{-3}\right.$; the average includes grid points with $\left.\left|\mathbf{u}_{h}\right|>5 \mathrm{~cm} \mathrm{~s}^{-1}\right)$.

located downstream the $\mathrm{AJ}$ ridge, reaching maxima of 30,15 , and $35\left(\times 10^{-5} \mathrm{~m} \mathrm{~s}^{-1}\right)$ in surveys $1,2,3$, respectively. Downwelling occurs upstream the trough of the AJ, where it impinges on the WAG, and downstream the AJ ridge (absent in survey 3 ). The largest downwelling velocities, obtained in survey 3 , are of -70 $\left(\times 10^{-5} \mathrm{~m} \mathrm{~s}^{-1}\right)$.

The two terms in the lhs of (9), $N^{2} \nabla_{h}^{2} w$ and $f(f+$ ל) $w_{z z}$ (not shown) have a similar distribution and are of the same order of magnitude $\left[O\left(10^{-16} \mathrm{~m}^{-1} \mathrm{~s}^{-3}\right)\right]$. On average $f(f+\zeta) w_{z z}$ is larger than $N^{2} \nabla_{h}^{2} w$ (Fig. 12).

Upwelling favors primary production in the photic layer, which can be detected in in situ fluorescence measurements (primary production). High values of chlorophyll fluorescence found in the northern and western Alboran Sea (Ruíz et al. 2001) probably indi- cate mesoscale upward motion, which in turn partially explains the fertilization in the northern and western part of the WAG. Other important processes affecting primary production in the western Alboran Sea are the advection of high productivity waters from the large scale coastal upwelling due to the effect of the AJ curvature and wind stress (Minas et al. 1991; Baldacci et al. 2001), as well as the time interval (approximately 1 week) needed by the microorganisms to transform the nutrients in new biomass detectable by fluorescence.

\section{d. Comparison with the $Q G$ theory}

The QG vertical velocity $w^{q}$, obtained from (11), is consistent with the pattern of a developing baroclinic meander (e.g., Holton 1992, his section 6.4), where upwelling occurs between trough and ridge, and down- 

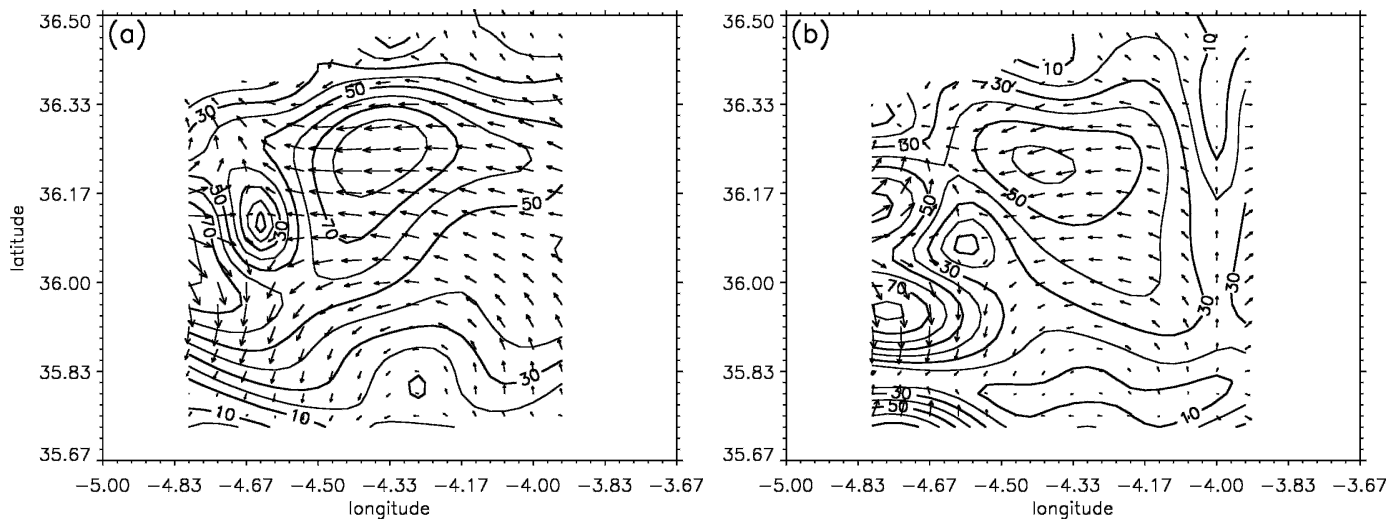

Fig. 21. The total (a) $\mathbf{Q}_{h}$ and geostrophic (b) $\mathbf{Q}_{h}^{g}$ for the survey 2. Isolines indicate the magnitude $\left|\mathbf{Q}_{h}\right|$ and $\left|\mathbf{Q}_{h}^{g}\right|\left(\Delta=10 \times 10^{-13} \mathrm{~s}^{-3}, z=-100 \mathrm{~m}\right)$.

welling between ridge and trough of the geopotential contours. Extreme values of $w^{q}$ reaching 45, 50, and 45 $\left(\times 10^{-5} \mathrm{~m} \mathrm{~s}^{-1}\right)$-surveys 1,2 , and 3 , respectively-are located where the flow changes curvature and the geostrophic speed is maximum. The distribution of $w^{q}$ in survey 1 (Fig. 17a) agrees with that obtained by Viúdez et al. (2000) and Gomis et al. (2001). Similar results were found in the California Current System with maxima of $O\left(40 \mathrm{~m} \mathrm{day}^{-1}\right)$, associated to mesoscale features with $\zeta \subset[-0.4 f, 0.6 f]$ at $100 \mathrm{~m}$ (Shearman et al. 1999).

The difference $w-w^{q}$ (Fig. 18) reaches absolute extrema of 50,40 , and $50\left(\times 10^{-5} \mathrm{~m} \mathrm{~s}^{-1}\right)$ in surveys 1,2 , and 3 , respectively. This difference is of the same order of magnitude as $w$ (Fig. 16). The root-mean-square (rms) difference between $w$ and $w^{q}$ (Fig. 19a) reaches maxima of about $17\left(\times 10^{-5} \mathrm{~m} \mathrm{~s}^{-1}\right)$ at $90-100 \mathrm{~m}$ for the three surveys. The horizontally averaged ratio $\left\langle w^{q} / w\right\rangle_{H}$ (Fig. 19b) is always larger than 1 except for survey 3.

The difference between the QG Eq. (11) and the generalized $\omega$ equation in terms of the $\mathbf{Q}$ vector (10) lies in the divergence of the ageostrophic vector $\mathbf{Q}_{h}^{\prime}$, the term $f \zeta_{\mathrm{ph}}^{\prime} \cdot \nabla_{h}^{2} \mathbf{u}_{h}$, and in the term $f \zeta w_{z z}$, being the first term larger than the two latter for the three surveys (Fig. 20). The importance of the horizontal divergence of the ageostrophic vector $\mathbf{Q}_{h}^{\prime}$ agrees with the results in Viúdez and Dritschel (2004) for flows having both positive and negative vorticity. The horizontal distributions of the total $\mathbf{Q}_{h}$ and geostrophic $\mathbf{Q}_{h}^{g}$ at $100 \mathrm{~m}$ for survey 2 (Fig. 21) shown significant differences in magnitude and direction, and as a consequence the ageostrophic vector $\mathbf{Q}_{h}^{\prime}$ is important in the diagnosis of the mesoscale vertical velocity. The rms difference between $w$ and the vertical velocity obtained from adding the term $2 \boldsymbol{\nabla}_{h} \cdot \mathbf{Q}_{h}^{\prime}$ to the rhs of (11) (Figs. 19a,c) is significantly smaller with the maximum shifted up in the water column $(50-80 \mathrm{~m})$. This shift is due to the fact that
$2 \boldsymbol{\nabla}_{h} \cdot \mathbf{Q}_{h}^{\prime}$ reaches maximum values in the surface layers. The horizontal distribution of $2 \boldsymbol{\nabla}_{h} \cdot \mathbf{Q}_{h}^{\prime}$ (Fig. 22) is of opposite sign to $2 \boldsymbol{\nabla}_{h} \cdot \mathbf{Q}_{h}^{g}$ (not shown). Thus, the addition of the term $2 \boldsymbol{\nabla}_{h} \cdot \boldsymbol{Q}_{h}^{\prime}$ reduces the divergence of $\mathbf{Q}_{h}^{g}$ and consequently reduces the magnitude of the vertical velocity (Fig. 19d). This reduction may be also inferred from the similarity between $2 \boldsymbol{\nabla}_{h} \cdot \mathbf{Q}_{h}^{\prime}$ (Fig. 22) and $w-$ $w^{q}$ (Fig. 18). The average of $\left\langle 2 \nabla_{h} \cdot \mathbf{Q}_{h}^{\prime}\right\rangle_{H}$ reaches maximum values larger than $8 \times 10^{-16} \mathrm{~m}^{-1} \mathrm{~s}^{-3}$ in the upper $50 \mathrm{~m}$ in survey 1 (Fig. 20).

\section{Concluding remarks}

In this paper we have diagnosed the mesoscale vertical velocity using density and horizontal velocity data from three consecutive quasi-synoptic, high-resolution surveys in the Alboran Sea. The diagnosis implies solving a generalized $\omega$ equation, proposed in Viúdez and Dritschel (2004) and solved here for the first time, which includes both density and horizontal velocity. The data analysis suggests a new interpretation of the pattern of vertical velocity based on the horizontal advection by the vertical shear velocity of the vertical component of vorticity. A similar "forcing" term, derived from the difference between the horizontal divergence at two levels, was used by Sutcliffe (1947) to obtain upward motion in the atmosphere.

Important differences have been found with respect to the QG approximation. These differences seem to be related to the large ageostrophic flow in the upper Alboran Sea, which may reach Rossby numbers of 0.9 at the surface. In terms of the $\mathbf{Q}$-vector form of the $\omega$ equation, these differences are partially accounted for by including the ageostrophic part of the $\mathbf{Q}$ vector. The total $\mathbf{Q}$ vector may significantly differ from its geostrophic counterpart.

Though more experimental studies are needed to 

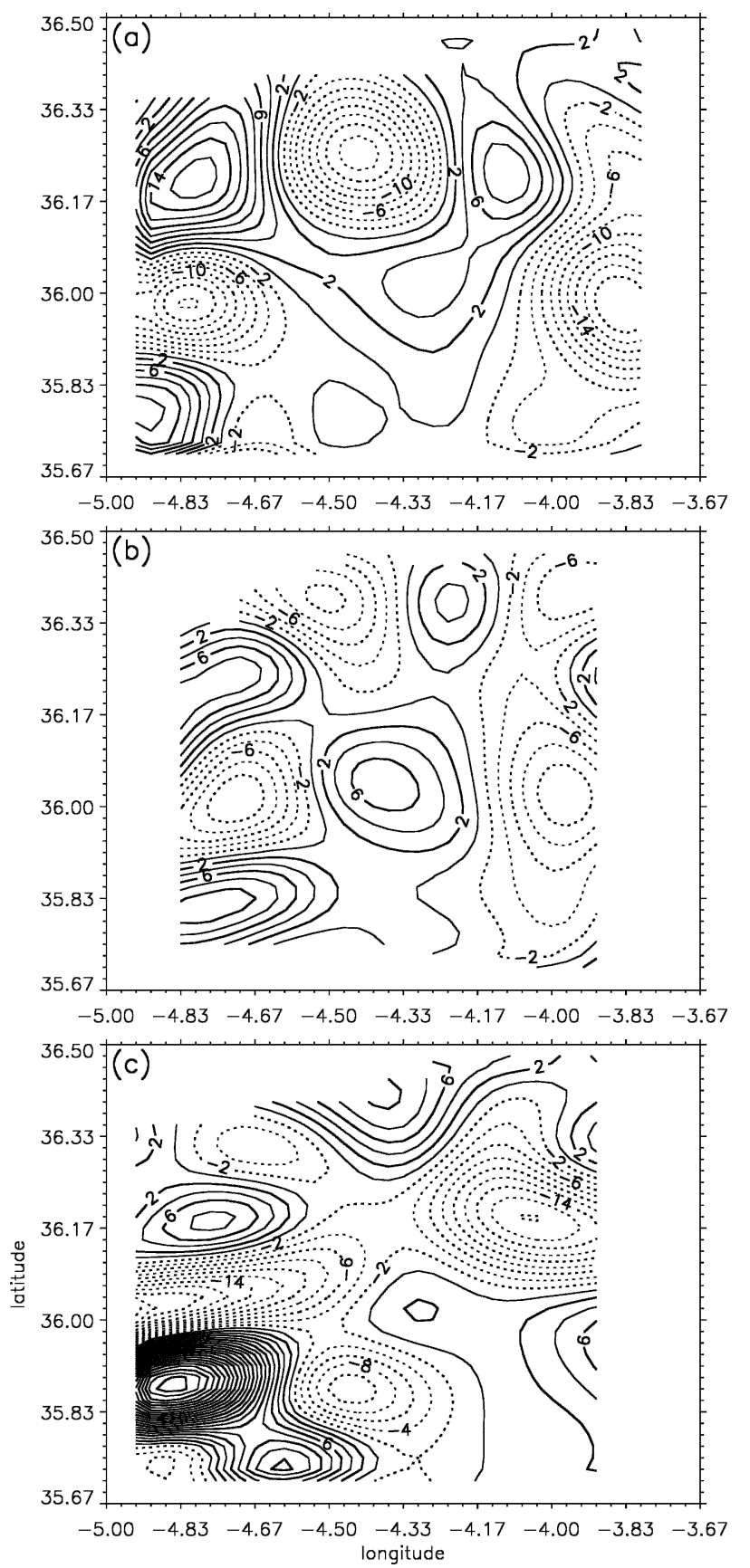

FIG. 22. Term $2 \boldsymbol{\nabla}_{h} \cdot \mathbf{Q}_{h}^{\prime}$ for the three surveys $\left(\Delta=2 \times 10^{-16}\right.$ $\left.\mathrm{m}^{-1} \mathrm{~s}^{-3}, z=-100 \mathrm{~m}\right)$.

corroborate the generality of these results, we conclude that estimates of the mesoscale vertical velocity can be improved beyond the QG approximation, and in particular for large ageostrophic flows, solving a generalized $\omega$ equation as long as regular, accurate, and synoptic horizontal velocity and density data are available. Thus, the results suggest that the method of obtaining the vertical velocity from density and horizontal veloc- ity is practical depending on the quality of the horizontal velocity data. For this purpose, the quality of the horizontal velocity data may be estimated from the magnitude of its horizontal divergence.

Acknowledgments. We acknowledge an FPU grant (AP2002-1895) and a research grant (REN2002-01343) from the Spanish Ministerio de Ciencia y Tecnología. Our thanks are given to C. Chapple for his help, S. Vallina for many fruitful discussions and helpful advice, and two anonymous reviewers for their comments.

\section{APPENDIX}

\section{Error Estimates in $\nabla_{h}^{2} \mathbf{u}_{h}$}

The accuracy in the vertical velocity obtained from the $\omega$ equations depends on the theoretical approximations (Snyder et al. 1991; Pedder and Thorpe 1999; Naveira Garabato et al. 2001), the presence of inertiagravity waves (Viúdez and Dritschel 2003, 2004) and tides (Naveira Garabato et al. 2001), the degree of synopticity of the experimental data (Viúdez et al. 2000; Rixen et al. 2001a,b; Rixen and Beckers 2002), and the interpolation method (Tintoré et al. 1991; Gomis et al. 2001), as well as the instrumental errors.

A measure of the combined effect of these errors is the horizontal divergence $\boldsymbol{\nabla}_{h} \cdot \mathbf{u}_{h}$. Although the actual

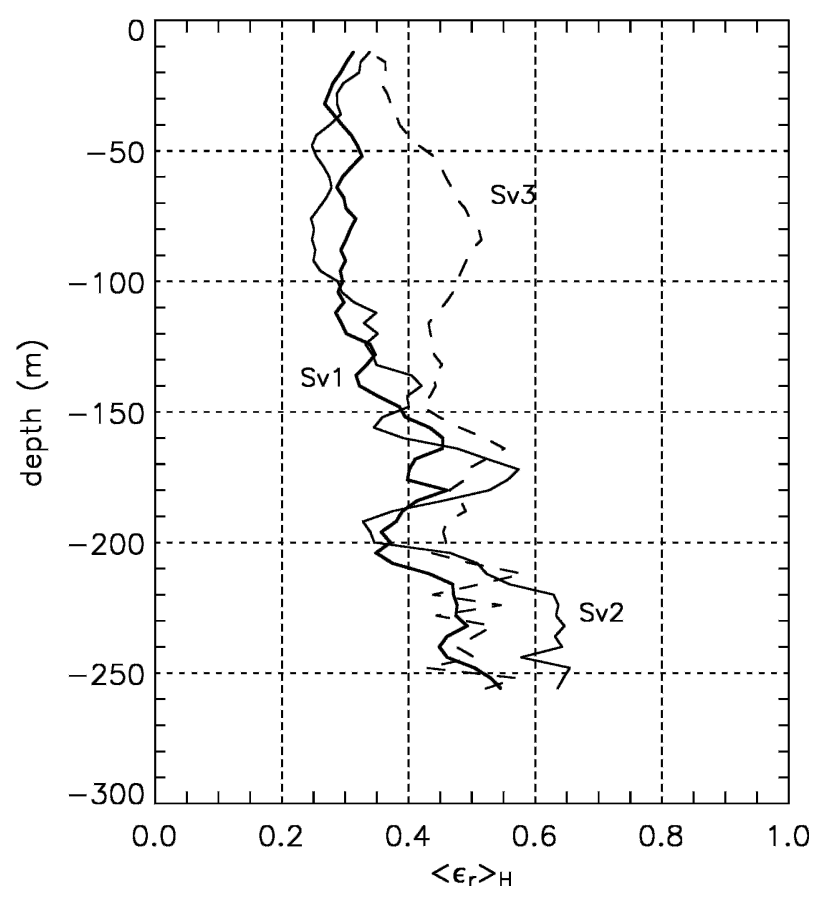

FIG. A1. The horizontally averaged relative error $\left\langle\varepsilon_{r}\right\rangle_{H}$ as a function of depth for the three surveys. 
flow preserves the volume $(\boldsymbol{\nabla} \cdot \mathbf{u}=0)$, unrealistically large values of $w$ are obtained when the experimental and interpolated $\mathbf{u}_{h}$ is used in the volume conservation equation $w_{z}=-\boldsymbol{\nabla}_{h} \cdot \mathbf{u}_{h}$ to derive the vertical velocity. We take, therefore, $\varepsilon \equiv \nabla_{h} \cdot \mathbf{u}_{h}$ as a measure of the total error, including the lack of synopticity, as well as interpolation, and instrumental errors. Adding random errors to the ADCP velocity is not a very useful approach to validate the robustness of the results because the interpolation procedure will filter these high-wavenumber components. To relate $\varepsilon$ to the error in $\nabla_{h}^{2} \mathbf{u}_{h}$ we use the vector identity

$$
\nabla_{h}\left(\nabla_{h} \cdot \mathbf{u}_{h}\right)=\nabla_{h}^{2} \mathbf{u}_{h}+\nabla_{h} \times\left(\nabla_{h} \times \mathbf{u}_{h}\right),
$$

so that the error associated to $\left|\nabla_{h}^{2} \mathbf{u}_{h}\right|$ is $\left|\nabla_{h} \varepsilon\right|$. The relative error is

$$
\varepsilon_{r}=\left|\nabla_{h} \varepsilon\right|\left|\nabla_{h}^{2} \mathbf{u}_{h}\right| .
$$

The horizontally averaged relative error $\left\langle\varepsilon_{r}\right\rangle_{H}$ (Fig. A1) is smaller than 1 in the three surveys. Minima (0.25) occur in the upper $150 \mathrm{~m}$ in surveys 1 and 2, while in the upper $150 \mathrm{~m}$, the maximum $(0.5)$ occurs at about $80 \mathrm{~m}$ in survey 3. This error is probably due to the local acceleration, or time variability, of the horizontal current $\partial \mathbf{u}_{h} / \partial t$, which is expected to be larger in survey 3 .

\section{REFERENCES}

Allen, J. S., 1993: Iterated geostrophic intermediate models. $J$. Phys. Oceanogr., 23, 2447-2461.

Allen, J. T., and D. A. Smeed, 1996: Potential vorticity and mesoscale vertical velocity at the Iceland-Færoes front. J. Phys. Oceanogr., 26, 2611-2634.

__ and Coauthors, 1997: Upper ocean underway operations on BIO Hespérides cruise OMEGA-ALGERS using SeaSoar and ADCP. Southampton Oceanography Centre Internal Rep. 17, 52 pp.

Baldacci, A., G. Corsini, R. Grasso, G. Manzella, J. T. Allen, P. Cipollini, T. H. Guymer, and H. M. Snaith, 2001: A study of the Alboran Sea mesoscale system by means of empirical orthogonal function decomposition of satellite data. J. Mar. Syst., 29, 293-311.

Bryden, H. L., 1973: New polynomials for thermal expansion, adiabatic temperature gradient and potential temperature gradient of sea water. Deep-Sea Res., 20, 401-408.

- 1980: Geostrophic vorticity balance in a midocean. J. Geophys. Res., 85, 2825-2828.

Davies-Jones, R., 1991: The frontogentical forcing of secondary circulations. Part I: The duality and generalization of the $Q$ vector. J. Atmos. Sci., 48, 497-509.

García Lafuente, J., and J. Delgado, 2004: The meandering path of a drifter around the Western Alboran Gyre. J. Phys. Oceanogr., 34, 685-692.

Gascard, J. C., and C. Richez, 1985: Water masses and circulation in the western Alboran Sea and in the Straits of Gibraltar. Progress in Oceanography, Vol. 15, Pergamon, 157-216.

Gill, A. E., 1982: Atmosphere-Ocean Dynamics. Academic Press, $662 \mathrm{pp}$.
Gomis, D., S. Ruíz, and M. A. Pedder, 2001: Diagnostic analysis of the 3D ageostrophic circulation from a multivariate spatial interpolation of CTD and ADCP data. Deep-Sea Res., 48A, 269-295.

Holton, J. R., 1992: An Introduction to Dynamic Meteorology. Academic Press, 511 pp.

Hoskins, B. J., and I. Draghici, 1977: The forcing of ageostrophic motion according to the semi-geostrophic equations and in an isentropic coordinate model. J. Atmos. Sci., 34, 1859-1867.

,$- \ldots$, and H. C. Davies, 1978: A new look at the $\omega$-equation. Quart. J. Roy. Meteor. Soc., 104, 31-38.

Hunt, J., A. Wrap, and P. Moin, 1988: Eddies, stream, and convergence zones in turbulent flows. Proc. CTR Summer Program, Stanford, CA, Center for Turbulence Research, 193208.

Isern-Fontanet, J., E. García-Ladona, and J. Font, 2003: Identification of marine eddies from altimetric maps. J. Atmos. Oceanic Technol., 20, 772-778.

Leach, H., 1987: The diagnosis of synoptic-scale vertical motion in the seasonal thermocline. Deep-Sea Res., 34, 2005-2017.

Lindstrom, S. S., and D. Watts, 1994: Vertical motion in the Gulf Stream near $68^{\circ}$ W. J. Phys. Oceanogr., 24, 2321-2333.

Minas, H. J., B. Coste, P. Lecorre, M. Minas, and P. Raimbault, 1991: Biological and geochemical signatures associated with the water circulation through the Strait of Gibraltar and in the western Alboran Sea. J. Geophys. Res., 96, 8755-8771.

Naveira Garabato, A. C., J. T. Allen, H. Leach, V. H. Strass, and R. T. Pollard, 2001: Mesoscale subduction at the Antarctic polar front driven by baroclinic instability. J. Phys. Oceanogr., 31, 2087-2107.

Panofsky, H. A., 1946: Methods of computing vertical motion in the atmosphere. J. Meteor., 3, 45-49.

Parrilla, G., and T. H. Kinder, 1987: The physical oceanography of the Alboran Sea. Reports in Meteorology and Oceanography, Rep. 40, Vol. 1, Harvard University, 143-184. [Available from Oceanographic Group, Division of Applied Sciences, Harvard University, Cambridge, MA 02138.]

Pauley, P. M., and S. J. Nieman, 1992: A comparison of quasigeostrophic and nonquasigeostrophic vertical motions for a model-simulated rapidly intensifying marine extratropical cyclone. Mon. Wea. Rev., 120, 1108-1134.

Pedder, M. A., 1989: Limited area kinematic analysis by a multivariable statistical interpolation method. Mon. Wea. Rev., 117, 1695-1708.

_ 1993: Interpolation and filtering of spatial observations using successive corrections and Gaussian filters. Mon. Wea. Rev., 121, 2889-2902.

_ and A. J. Thorpe, 1999: The semi-geostrophic diagnosis of vertical motion. I: Formulation and coordinate transformations. Quart. J. Roy. Meteor. Soc., 125, 1231-1256.

Pinot, J.-M., J. Tintoré, and D.-P. Wang, 1996: A study of the omega equation for diagnosing vertical motions at ocean fronts. J. Mar. Res., 54, 239-259.

Pollard, R. T., and L. A. Regier, 1992: Vorticity and vertical circulation at an ocean front. J. Phys. Oceanogr., 22, 609-625.

Rixen, M., and J.-M. Beckers, 2002: A synopticity test of a sampling pattern in the Alboran Sea. J. Mar. Syst., 35, 111-130.

,$- \ldots$, and J. T. Allen, 2001a: Diagnosis of mesoscale vertical velocities with the $\mathrm{QG}$ omega equation: A relocation method to obtain pseudo-synoptic data sets. Deep-Sea Res., 48A, $1347-1373$

_, J. T. Allen, and J.-M. Beckers, 2001b: Non-synoptic versus 
pseudo-synoptic data sets: An assimilation experiment. $J$. Mar. Syst., 29, 313-333.

Rudnik, D. L., 1996: Intensive surveys of the Azores front, Part 2: Inferring the geostrophic and mesoscale vertical velocity fields. J. Geophys. Res., 101, 16 291-16 303.

Ruíz, J., and Coauthors, 2001: Surface distribution of chlorophyll, particles and gelbstoff in the Atlantic Jet of the Alboran Sea: From submesoscale to subinertial scales of variability. J. Mar. Syst., 29, 277-292.

Shearman, R. K., J. A. Barth, and P. M. Kosro, 1999: Diagnosis of the three-dimensional circulation associated with mesoscale motion in the California Current. J. Phys. Oceanogr., 29, 651670.

- _ J. S. Allen, and R. L. Haney, 2000: Diagnosis of the three-dimensional circulation in mesoscale features with large Rossby number. J. Phys. Oceanogr., 30, 2687-2709.

Sherman, L., 1953: Estimates of the mesoscale vertical velocity based on the vorticity equation. J. Meteor., 10, 399-400.

Snyder, C., W. C. Skamarock, and R. Rotunno, 1991: A comparison of primitive-equation and semigeostrophic simulations of baroclinic waves. J. Atmos. Sci., 48, 2179-2194.

Sutcliffe, R. C., 1947: A contribution to the problem of development. Quart. J. Roy. Meteor. Soc., 73, 370-383.

Tintoré, J., D. Gomis, S. Alonso, and G. Parrilla, 1991: Mesoscale dynamics and vertical motion in the Alboran Sea. J. Phys. Oceanogr., 21, 811-823.

Trenberth, K. E., 1978: On the interpretation of the diagnostic quasi-geostrophic omega equation. Mon. Wea. Rev., 106, 131-137.

Truesdell, C., 1953: Two measures of vorticity. J. Ration. Mech. Anal., 2, 173-217.

— 1954: Kinematics of Vorticity. Indiana University Press, 232 pp.

UNESCO, 1981: The practical salinity scale 1978 and the international equation of state for seawater 1980: Tenth report of the joint panel on oceanographic tables and standards. UNESCO Tech. Papers in Marine Science 36, Paris, France.

Vargas-Yáñez, M., F. Plaza, J. García-Lafuente, T. Sarhan, J. M.
Vargas, and P. Vélez-Belchi, 2002: About the seasonal variability of the Alboran Sea circulation. J. Mar. Syst., 35, 229248.

Viúdez, A., and R. L. Haney, 1997: On the relative vorticity of the Atlantic Jet in the Alboran Sea. J. Phys. Oceanogr., 27, 175195.

- and D. G. Dritschel, 2003: Mesoscale vertical velocity in mesoscale geophysical flows. J. Fluid Mech., 483, 199-223.

— and - 2004: Potential vorticity and the quasigeostrophic and semigeostrophic mesoscale vertical velocity. J. Phys. Oceanogr., 34, 865-887.

_ J. Tintoré, and R. L. Haney, 1996a: Circulation in the Alboran Sea as determined by quasi-synoptic hydrographic observations. Part I: Three-dimensional structure of the two anticyclonic gyres. J. Phys. Oceanogr., 26, 684-705.

$\longrightarrow$, R. L. Haney, and J. Tintoré, 1996b: Circulation in the Alboran Sea as determined by quasi-synoptic hydrographic observations. Part II: Mesoscale ageostrophic motion diagnosed through density dynamical assimilation. J. Phys. Oceanogr. 26, 706-724.

- J. Tintoré, and R. L. Haney, 1996c: About the nature of the generalized omega equation. J. Atmos. Sci., 53, 787-795.

_ - J.-M. Pinot, and R. L. Haney, 1998a: On the upper layer circulation in the Alboran Sea. J. Geophys. Res., 103, $21653-$ 21666.

—, R. L. Haney, and J. Vázquez-Cuervo, 1998b: The deflection and division of an oceanic baroclinic jet by a coastal boundary: A case study in the Alboran Sea. J. Phys. Oceanogr., 28, 289-308.

,-- , and J. T. Allen, 2000: A study of the balance of horizontal momentum in a vertical shearing current. J. Phys. Oceanogr., 30, 572-589.

William, H. P., B. P. Flannery, S. A. Teukolsky, and W. T. Vetterling, 1993: Numerical Recipes in FORTRAN 77. 2d ed., Cambridge University Press, 992 pp.

Xu, Q., 1992: Ageostrophic pseudovorticity and geostrophic Cvector forcing-A new look at the $\mathbf{Q}$ vector in three dimensions. J. Atmos. Sci., 49, 981-990. 